\title{
Research Paper \\ Analysis of the Status of Sustainable Entrepreneurship in Macro and Sectorial Agricultural Policies of the Islamic Republic of Iran
}

\author{
*Pegah Moridsadat ${ }^{1}$, Abdol Reza Roknoddin Eftekhari², Mahdi Pour Taheri ${ }^{3}$, Hossein Shabanali Fami ${ }^{4}$
}

1. Assistant Professor, Department of Geography and Spatial Planning, Faculty of Earth Sciences, Shahid Beheshti University, Tehran, Iran.

2. Professor, Department of Geography and Rural Planning, Faculty of Humanities, Tarbiat Modares University, Tehran, Iran.

3. Associate Professor, Department of Geography and Rural Planning, Faculty of Humanities, Tarbiat Modares University, Tehran, Iran.

4. Associate Professor, Department of Agriculture Development, Faculty of Economic and Agriculture Development, College of Agriculture \& Natural Resources, University of Tehran, Tehran, Iran.

\begin{tabular}{|l|l|}
\hline $\begin{array}{l}\text { Use vour device to scan } \\
\text { and read the article online }\end{array}$ & $\begin{array}{l}\text { Citation: Moridsadat, P., Roknoddin Eftekhari, A., Pour Taheri, M., \& Shabanali Fami, H. (2017). [Analysis of the Status of } \\
\text { Sustainable Entrepreneurship in Macro and Sectorial Agricultural Policies of the Islamic Republic of Iran (Persian)]. Journal of } \\
\text { Rural Research, 8(1), 82-99. http://dx.doi.org/10.21859/jjr-08016 }\end{array}$ \\
dol: : http://dx.doi.org/10.21859/jjr-08016
\end{tabular}

Received: 15 Jan. 2017

Accepted: 20 Feb. 2017

Key words:

Sustainable

entrepreneurship,

Agriculture, Policy,

Content analysis

\section{A B STR ACT}

Currently, according to the various challenges of sustainable agriculture development principles such as competitive market, new technologies, and environment protection, developing sustainable entrepreneurship in agriculture sector is introduced as a key and an effective strategy to achieve agricultural sustainability. For this purpose, it is essential to provide appropriate policies on economic, social, and environmental dimensions. The current study aimed at analyzing the status of dimensions and elements of sustainable entrepreneurship in macro and sectorial agricultural policies of Islamic Republic of Iran. Content analysis research method was used to analyze the policies. Hierarchical additive weighting method (HAW) and the Shannon entropy weighting method were used to prioritize the 5-year development plan. The results showed that the entrepreneurship term was used in the Islamic Republic of Iran policy documents from the second development plan. But, sustainable entrepreneurship term is not used yet. Therefore, the sustainable entrepreneurship thought should be entered into the national policy. Due to entering the sustainability and entrepreneurial thought, and the terms related to the components of sustainable entrepreneurship in the policy documents of I.R.I, there is no obstacle to enter sustainable entrepreneurship thought in macro and sectorial policies including the constitutional law and Iran outlook 1404 and its policies, and 5 year development plans. According to the status of importance of sustainable entrepreneurship dimensions in 5 year development plan documents, the second plan is in first priority and then there are first, fifth, forth, and third plans.

\section{Extended Abstract}

\section{Introduction}

he failure of growth-oriented agricultur-

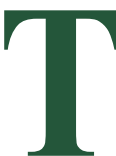

al policies in the framework of modernization theory and market failure caused economic, social, and environmental unsustainability in agricultural sector. In addition, currently sustainable agriculture development is faced with numerous challenges in global, regional, and local levels. Improving productions and productivity, profitability, marketing, health and food security, employment, modern technologies development, farmers empowerment, and environment protection on one hand, and some evolutions such as globalization, decentralization and privatization, competitive and free markets, population growth and urbanization, changes in the agricultural

\section{* Corresponding Author:}

Pegah Moridsadat, PhD

Address: Department of Geography and Spatial Planning, Faculty of Earth Sciences, Shahid Beheshti University, Tehran, Iran.

Tel: +98 (921) 7614191

E-mail: p_moridsadat@sbu.ac.ir 
labor market, the necessity of research and development and innovation, developing the new food products, and changing the consumption patterns and consumer interests, climate changes, and environmental hazards on the other hand are the most important challenges that should be considered to make agricultural policies. Thus, the need to develop sustainable agriculture by adopting effective strategies and making appropriate policies is emphasized. In this regard, developing sustainable entrepreneurship in agriculture sector is introduced as a key and an effective strategy to achieve agricultural sustainability. In the entrepreneurial literatures, failure of markets is the resource of opportunities for sustainable entrepreneurs to achieve profitability and simultaneously reduce environmental degradations and realize social goals.

Developing new products and services, radical technologies, innovative methods of marketing, improving business models and practices, and increasing efficiency are some of the opportunities to emerge sustainable entrepreneurship and create economic, social, and environmental values. In this framework, developing sustainable entrepreneurship in agricultural sector facilitates the achievement of the goals of sustainable agriculture, especially wealth and human and ecosystem welfare by empowering farmers, increasing the number of sustainable farms, developing effective innovations and technologies, and more green products. For this purpose, it is essential to provide appropriate policies on economic, social, and environmental dimensions. In this framework, the current study aimed at analyzing the status of dimensions and elements of sustainable entrepreneurship in macro and sectorial agricultural policies of Islamic Republic of Iran.

\section{Methodology}

The content analysis research method was used to analyze the policies. The qualitative research method was employed to study the attitudes of policy documents by coding rules to make quantities data. The constitutional law, Iran, outlook 1404 and its policies, general policies of the Islamic Republic of Iran, and the policies of 5 year development plan from first to fifth plan, were the policy documents analyzed in this article. The validity of the analysis was achieved via symmetrical validity through providing a valid measure based on reviewing valid literatures comprising sustainable development, sustainable entrepreneurship and agricultural entrepreneurship policy making, and the visions of expert panel. Finally, a measure was prepared to analyze the status of sustainable entrepreneurship in the selected policy documents that included economic, social, and environmental dimensions. Each of them consisted of some elements and sub elements.
Respectively, the dimensions included 4 (investment and infrastructure development, employment, trade and market, and productivity and profitability), 6 (justice, decentralization and participation, knowledge, culture, and empowerment, life quality, research and development, and institutional development), and 2 (natural resources conservation and rehabilitation; environmental management, and monitoring and evaluation) elements. Their sub-elements were used as recording and counting units. The reliability of this analysis was 0.987 . The hierarchical additive weighting method (HAW) of decision making models and the Shannon entropy weighting method were used to recognize the trend of emerging sustainable entrepreneurship dimensions in the 5 year development plans and prioritizing them.

\section{Results}

The results showed that the sustainable development term was used in some policy documents including the policies of Iran outlook 1404 (3 times), the general policies of water resources (1 time), Agriculture (1 time), and natural resources (1 time). In addition, it was used in the agricultural policies in the second (1 time), third (1 time) and fifth (1 time) 5 year development plan of I.R.I. Also, the entrepreneurship term entered some of these policy documents including the policies of Iran outlook 1404(2 times), the general policy of economic security (1 time), employment (2 times), and investment encouragement (1 time), and third (2 times) and forth (2 times) 5 year development plans. The multiple dimensions and components of sustainable entrepreneurship were used in the documents with different frequency and weights. The different weights of social (0.5), economic (0.3), and environmental (0.2) dimensions of the concept approve it.

\section{Discussion}

The results show that the entrepreneurship term has been used in the Islamic Republic of Iran policy documents from second development plan. But sustainable entrepreneurship term has not been used yet. In the national macro policies including the constitutional law and Iran outlook 1404 and its policies, the entrepreneurship term is used only twice (3\%) in the third document. The social dimension is the most frequent (more than about $70 \%$ ) in these documents. The findings of analyzing general policy documents were indicated that the environmental dimension was the most important in water resources, natural resources and adjustment of consumption samples policies. In contrast, in promoting investment and employment policy documents were focused on economic dimension and entrepreneurship recording unit 
was counted. There was not entrepreneurship term in the general agricultural policy documents. Also environmental dimension was neglected. There are various elements of sustainable entrepreneurship in the macro policies of five-year development plan and entrepreneurship word is used in the third and fourth documents. Emphasis on investment, knowledge, culture and empowerment and research and development elements has grown in these documents. From the first to fourth five-year development plans, social dimension is the most important but in the fifth priority is economic and then environmental dimensions. According to the status of importance of sustainable entrepreneurship dimensions in five-year development plan documents, the second plan is in first priority and then there are first, fifth, forth and third plan.

\section{Conclusion}

The macro and sectoral policies are supporting the sustainable entrepreneurship but there is not a holistic and integrated approach toward this in the documents. Especially, environmental dimension has been had very little importance and need to be reviewed. Also recognizing these documents is essential to make appropriate policies to develop sustainable entrepreneurship in agricultural sector. Because of scattering the components of sustainable entrepreneurship in the documents need to prepare a new macro policy document as a multi-sectorial guideline.

\section{Acknowledgments}

This research was extracted from the $\mathrm{PhD}$ thesis of the third author, Department of Geography and Rural Planning, Faculty of Humanities, Tarbiat Modares University, Tehran, Iran.

\section{Conflict of Interest}

The authors declared no conflicts of interest. 


\title{
واكاوى وضعيت كار آفرينى يايداردر سياستهاى كلان و بخشى كثاورزى جمهورى اسلامى ايران
}

\author{
•"بكاه مريدسادات'، عبدالرضا ركنالدين افتخارى"، مهدى يورطاهرى"، حسين شعبانعى فمى" \\ 1- استاديار، كروه جغرافيا وآمايش، دانشكده علوم زمين، دانشكاه شهيد بهشتى، تهرانه، ايران.

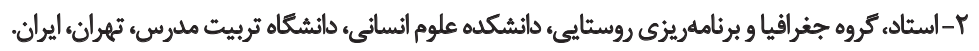

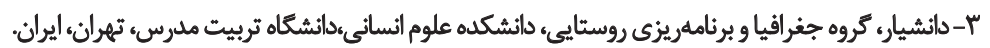

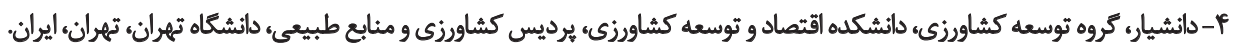

\begin{abstract}
حكSי

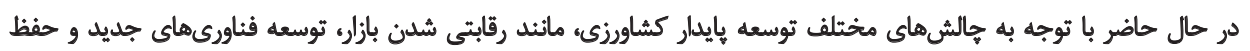

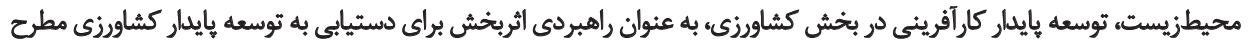

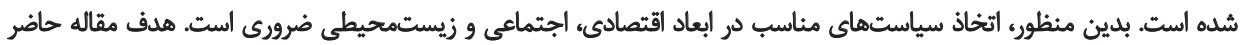

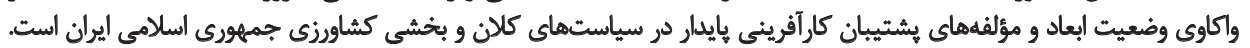

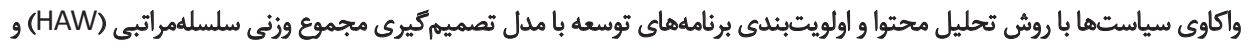

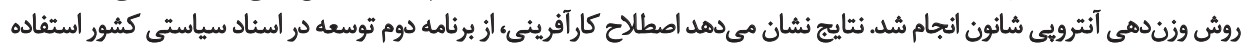

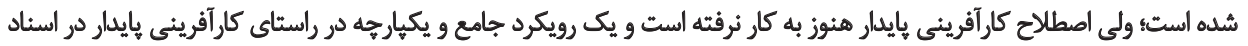

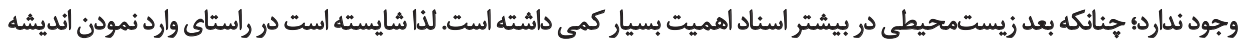

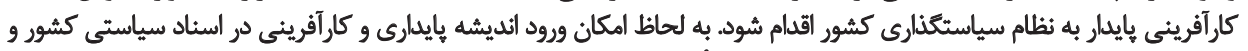

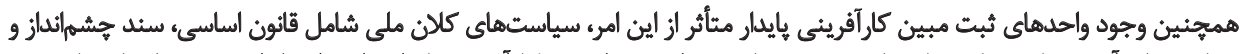

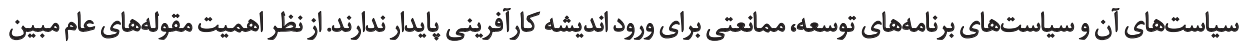

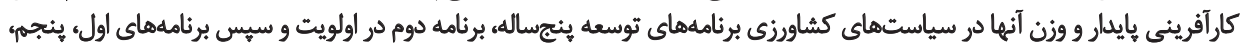

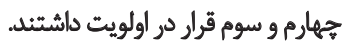

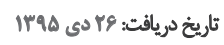

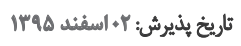

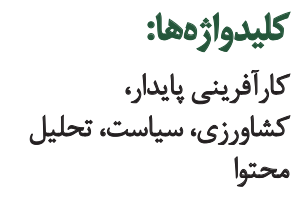

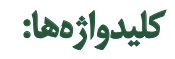

كارآرينى يايدار،

محتوا

اين حالشها و تحقق توسعه بايدار كشاورزى، اتخاذ سياستهاى

مقدمه

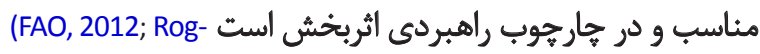
ers, Jalal, \& Boyd, 2008; pretty, 1998)

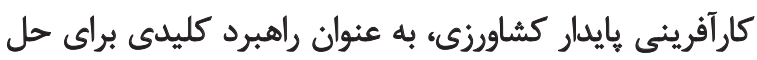

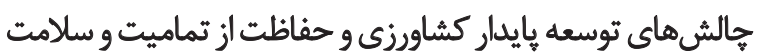

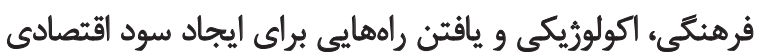

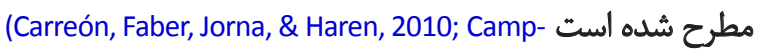
bell \& Barrett, 2008; McElwee, 2006; Sharifzadeh et al., 2009, Rokneddin Eftekhari, \& Sojasi Qedari, 2010) سياستهاى اثربخش جهث تحقق كارآفرينى ڤايدار كشاورزى (Bygrave \& Zacharakis, 2011; Kelley, Bosma, \& Amorós, 2010; g Didehvar, 2010; Rokneddin Eftekhari \& Sojasi Qedari, 2010) درنتيجه توسعه پايدار كشاورزى ثأكيد شده است.

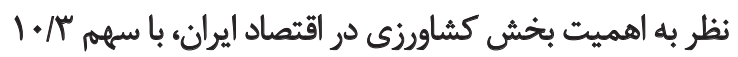

اتخاذ سياستهاي رشدمحور در جارجوب نظريه نوسازى

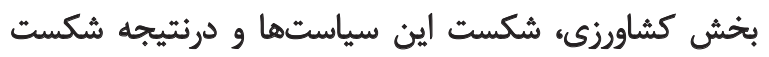

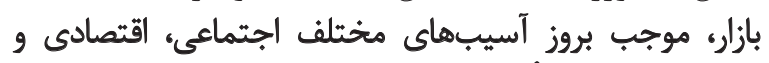

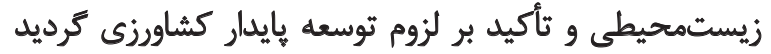

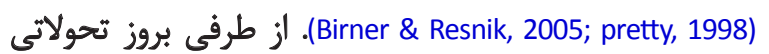

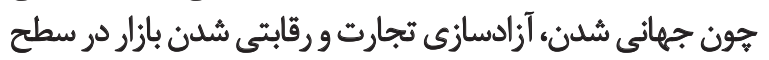

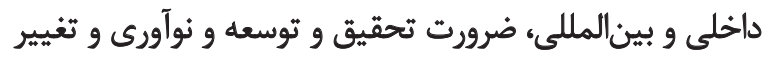

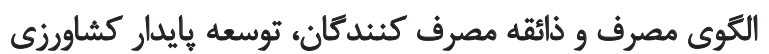

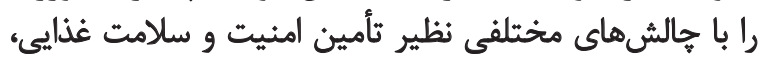

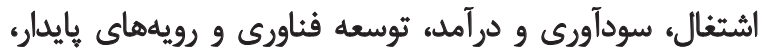

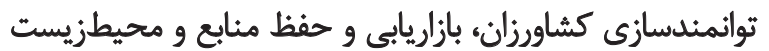

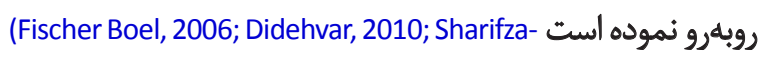
deh, Arabiuon, Yadollahi Farsi, \& Razavi, 2009).

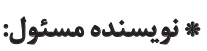

دكتر بكاه مريدسادات

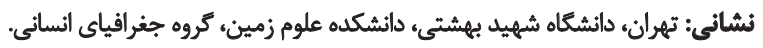
تلفن: p_moridsadat@sbu.ac.ir: يست الكترونيكي 
توجه به ابعاد و مؤلفههاي كار آفرينى يايدار جكونه بوده است؟ (T) الولويت و روند ميزان توجه به ابعاد كار آفرينى يايدار در دورههاي

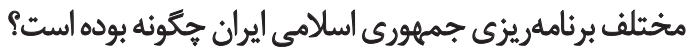

\section{مرورى بر ادبيات موضوع}

مطابق نظريههاى سنتى اقتصاد رفاه و محيطزيست، شكست بازار و شكست سياستهاى رشدكرايانه توسعه، علت بروز نإيايدارىهاى

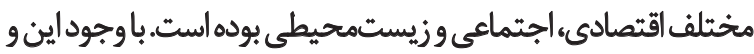

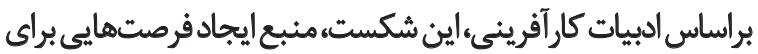

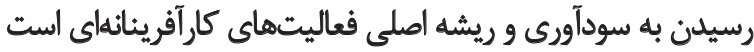

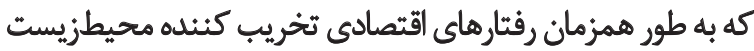

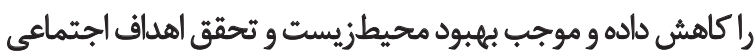

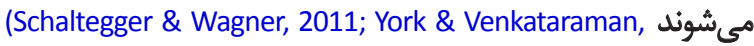

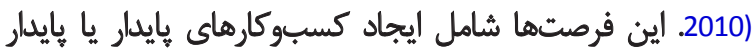

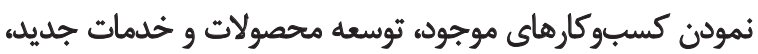

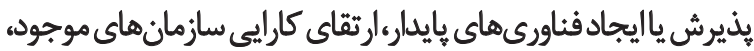

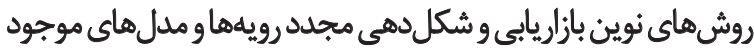

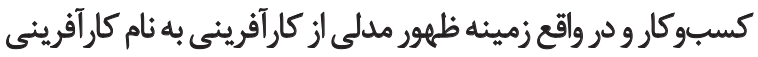

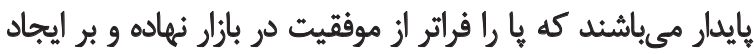

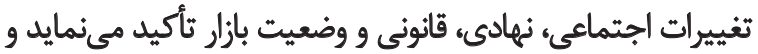

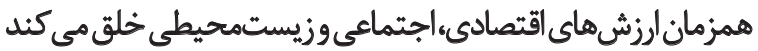

.(Schaltegger \& Wagner, 2011; Cohen \& Winn, 2007)

در اين خارجوب، توسعه بايدار كارآفرينى در بخش كشاورزى،

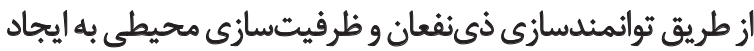

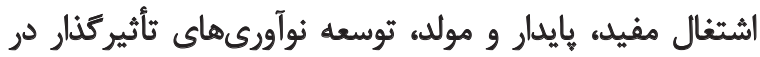

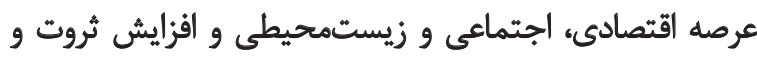

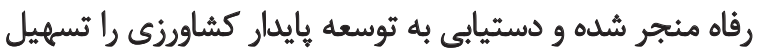

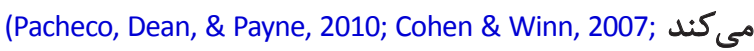
Rokneddin Eftekhari \& Sojasi Qedari, 2010)

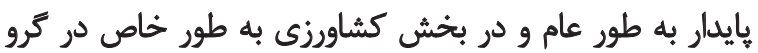

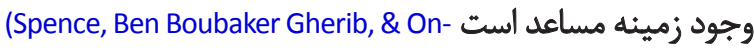
doua Biwolé 2010; Schaltegger \& Wagner, 2011; Pacheco et al., (2010. رويكرد رفتارى ونظريه تلفيقى كار آفرينى مبين مؤلفهائ

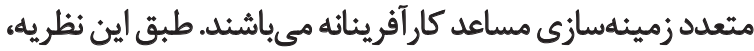

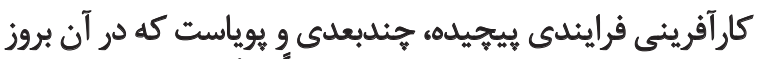

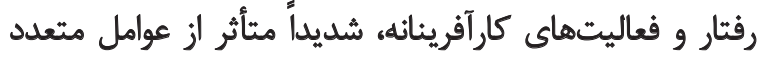

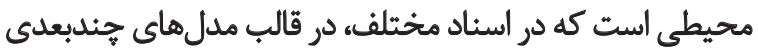

معرفى شدهاند (Ahmadpour Dariani, 2004; Eskandari, 2006).

در اين جارجوب؛ بر اتخاذ سياستهاي مناسب براي ايجاد

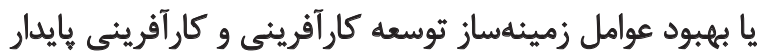

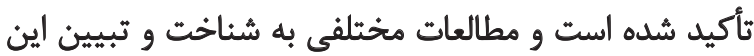

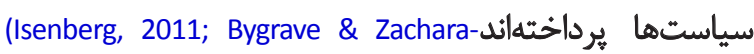
kis,2011; Kelley et al,2010; Stevenson \& lundstrom, 2007;

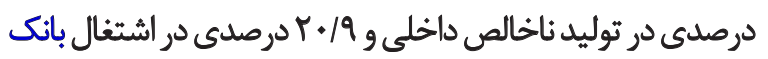

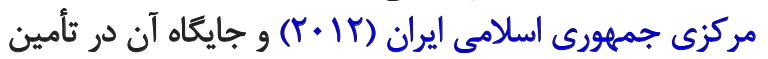

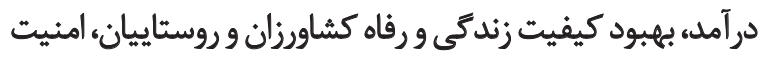

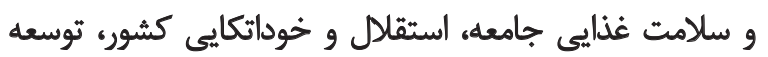

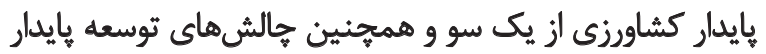

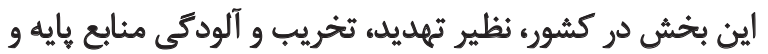

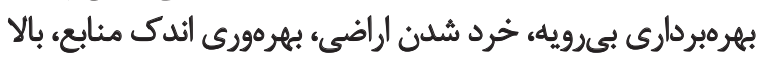

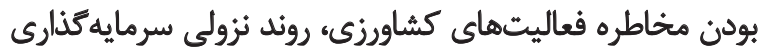

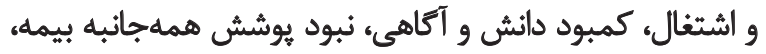

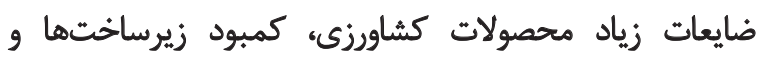

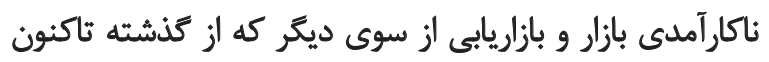

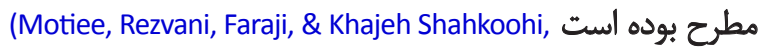
2010; Agricultural Planning Economic and Rural Development Research Institute, 2010; Management and Planning Organiza-

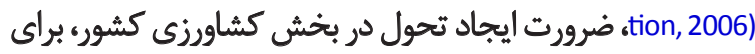

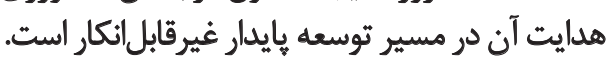

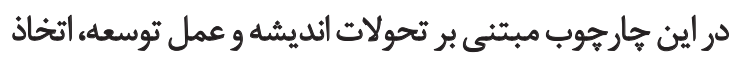

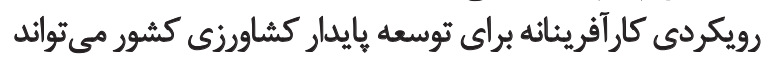

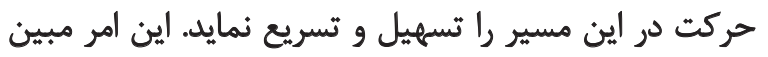

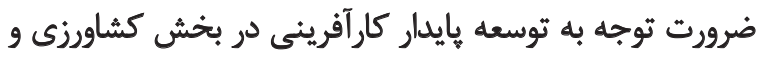

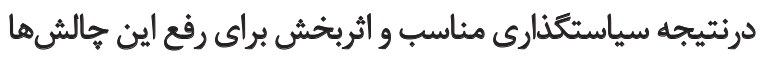

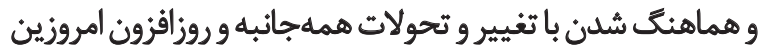

$$
\text { در عرصههاى خارجى و داخلى است. }
$$

در اين ميان لازمه اتخاذ رويكردى جديد در سياستخذارى تهاى

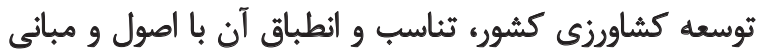

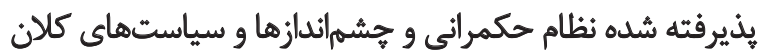

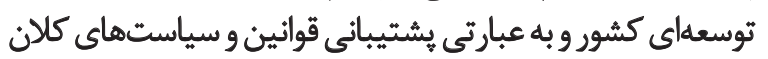

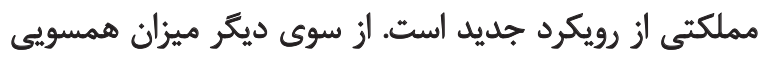

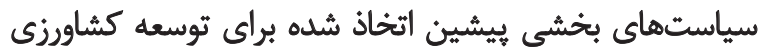

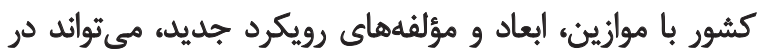

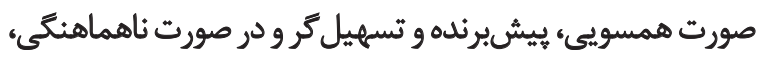

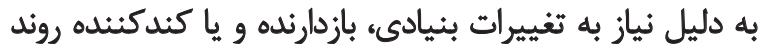

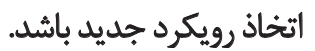
از اين رو هدف مقاله حاضر بر بايه واكاوى وضعيت كارآفرينى

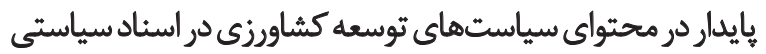

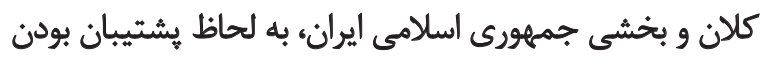

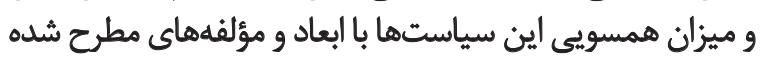

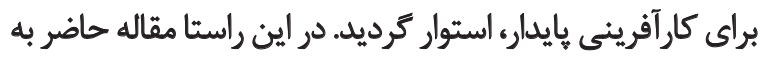

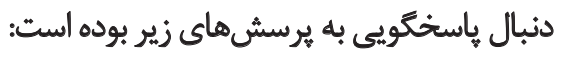

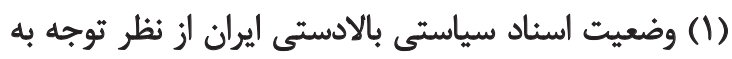

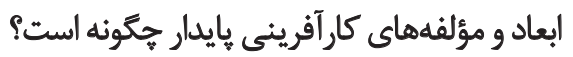
(r) وضعيت سياستهاى بخش كشاورزى در ايران، از نظر 


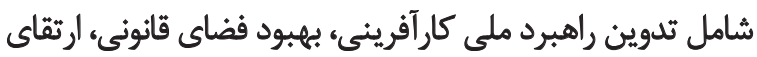

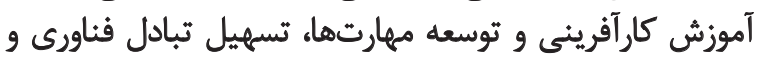

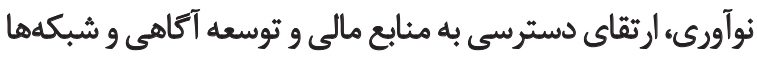
و اهداف و اقدامات متناظر بر آنها را ارائه نموده است

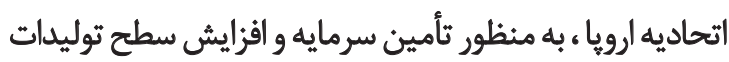

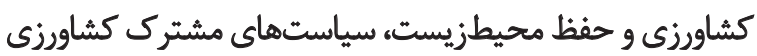

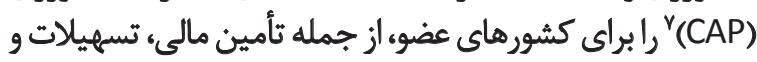

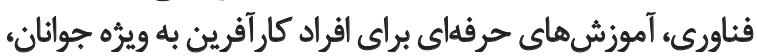

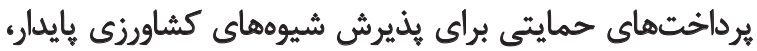

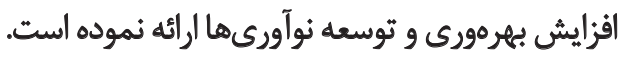

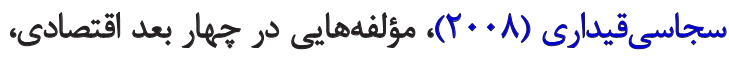

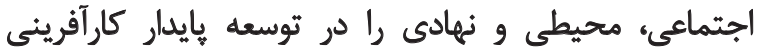

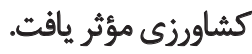

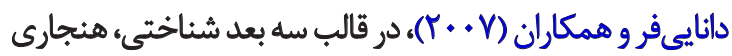

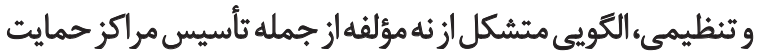

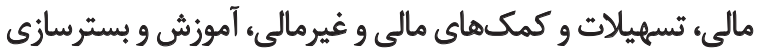
فرهنكى و اقدامات سياستى مرتبط با با آنها را الرائه نمودهاند.

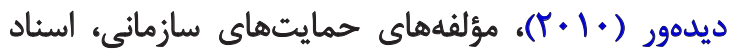

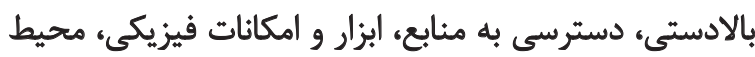

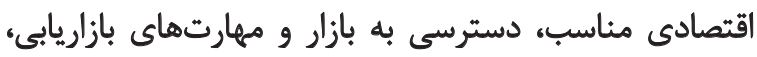
آموزش، هدايت و مشاوره، محيط اكولوزيك برئ كشاورزى و و منابيع طبيعى را براى نهادينهسازى كارآفرينى در بخش كشارئ كشاورزى

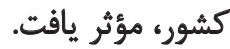

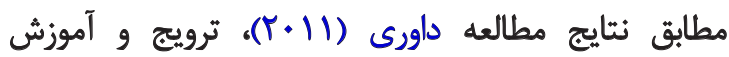

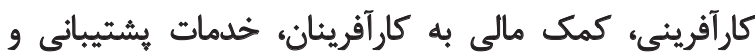

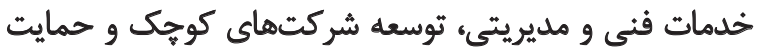

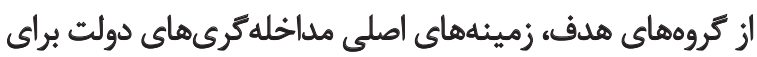
توسعه كارآفرينى هستند.

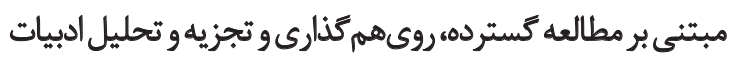

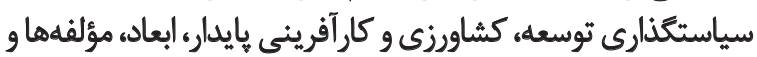

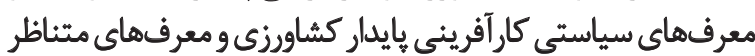

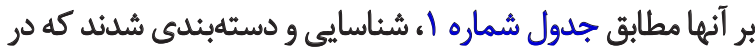
مقاله حاضر مبناى تحليل محتوا قرار كرفته است.

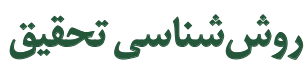

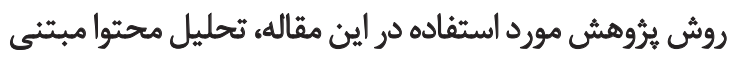

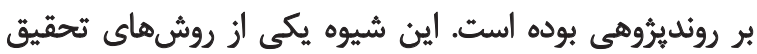

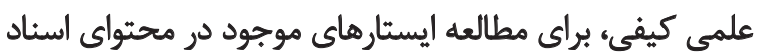

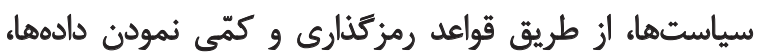

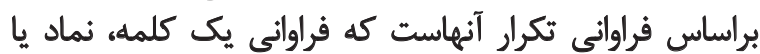

7. Common Agricultural Policy (CAP)
Didehvar, 2010; Rokneddin Eftekhari \& Sojasi Qedari, 2010)

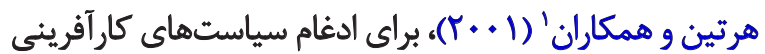

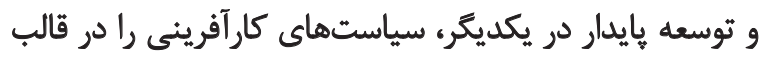

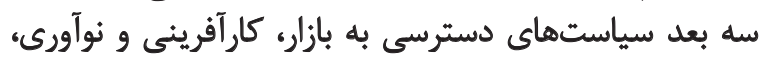

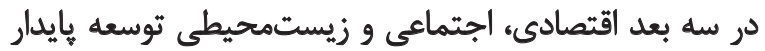

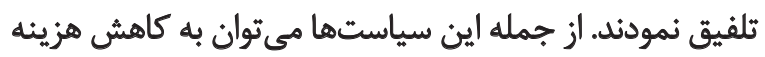

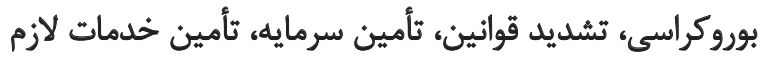

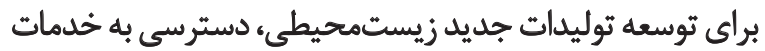

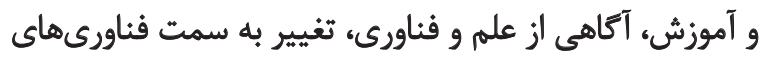

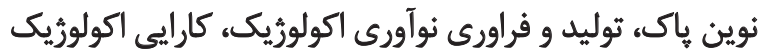

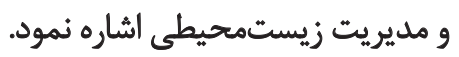

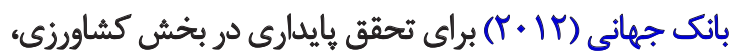

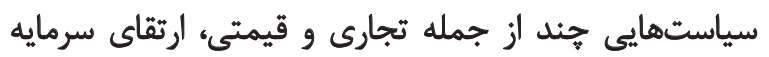

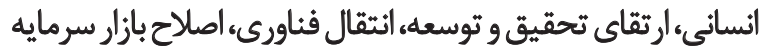

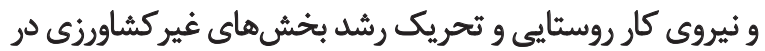
روستا را مورد تأكيد قرار داده است. تحريك

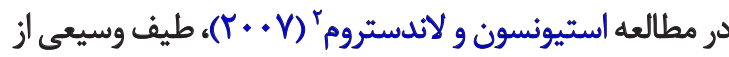

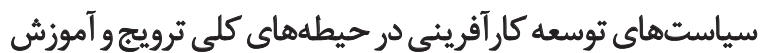

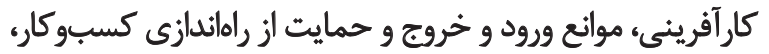

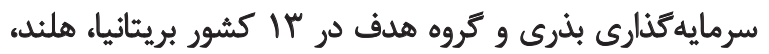

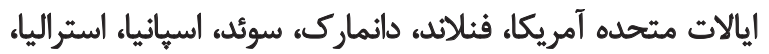

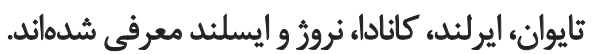

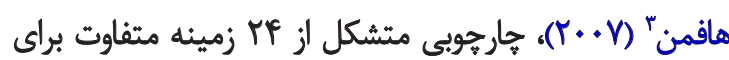

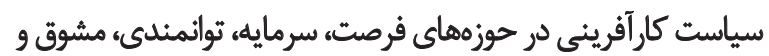

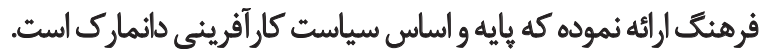

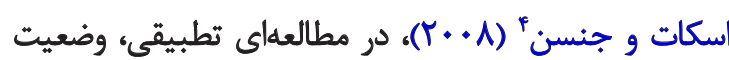

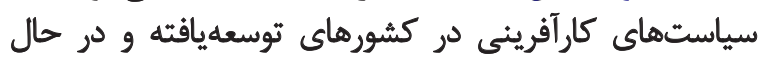

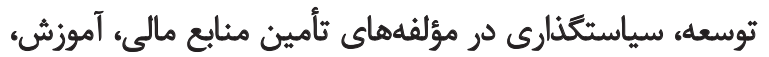

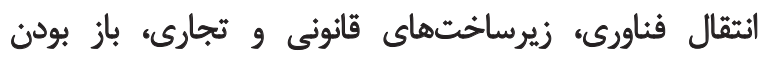

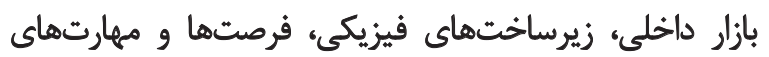

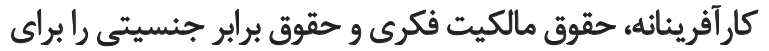
رشد كار آفرينائه مورد بررسي قالكيت فكرار دادني.

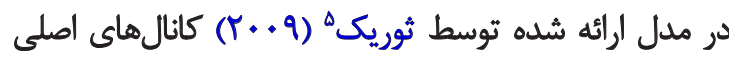

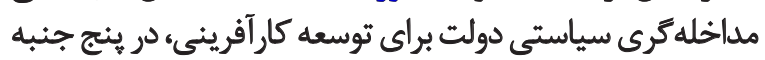

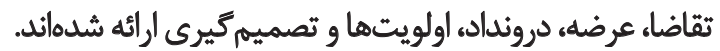
آنكتادو (Y (Y)، الكويى متشكل از شش زميئه كليدى سياستى

1. Hertin et al.

2. Stevenson \& lundstrom

3. Hoffman

4. Schøtt \& Jensen

5. Thurik

6. United Nations Conference on Trade and Development (UNCTAD) 
جدولي ا ابعاد، موالفهها و معرفهاي كار آفرينى ثايبار كشاورزى

\begin{tabular}{|c|c|c|}
\hline معرف & مولفه & بُعد \\
\hline 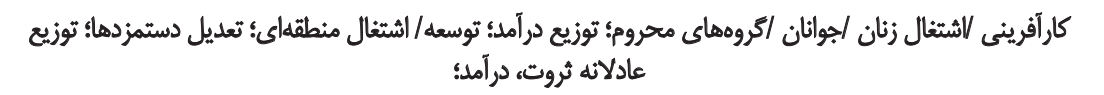 & عدالت و برابرى & \\
\hline 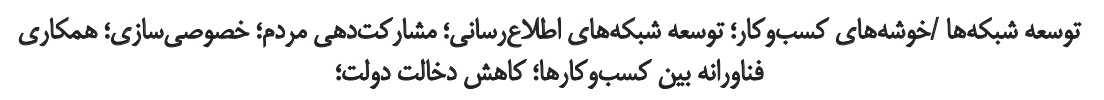 & تمركزيدايع و مشاركت & \\
\hline 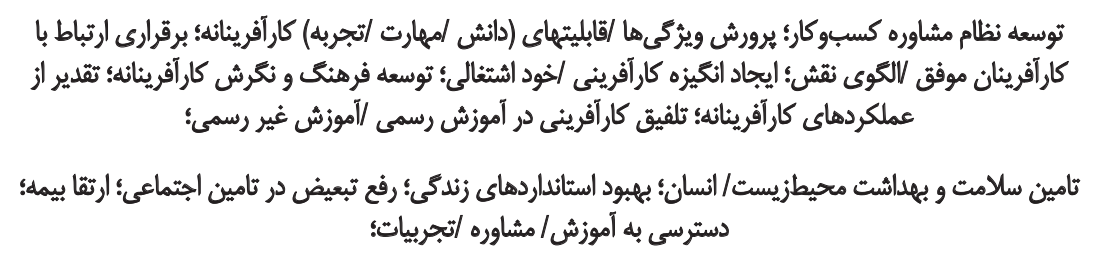 & دانش، فر هنك و توائمندسازى & \\
\hline 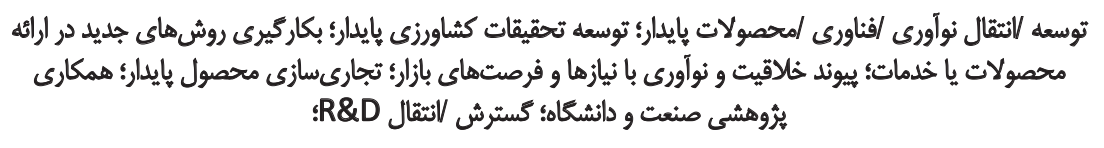 & تحقيق و توسعه & \\
\hline 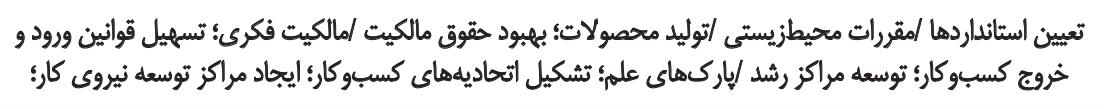 & ت توسعه نهادى & \\
\hline 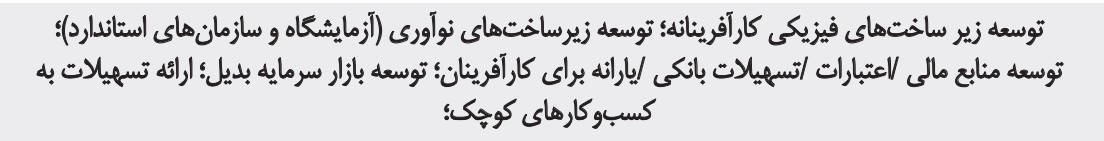 & سرمايهكنارى و توسعه & \\
\hline 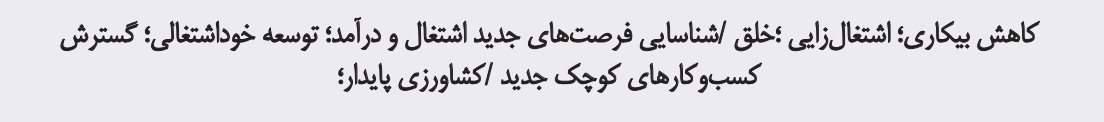 & الشتغلر & \\
\hline 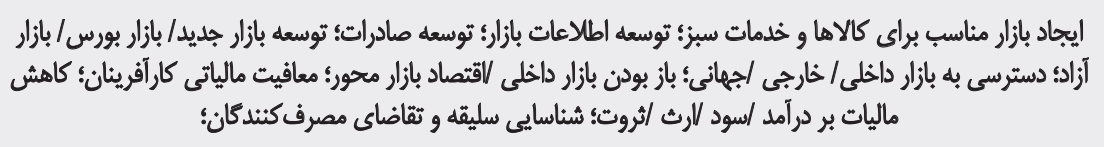 & تقجارت و بازار & 3 \\
\hline 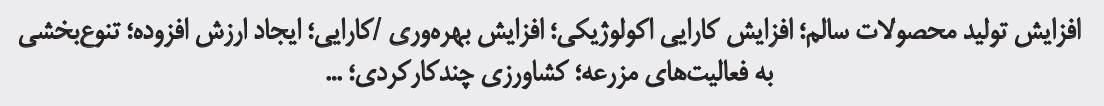 & بهرهورى و سودآورى & \\
\hline كاهش تخريب هحيط زيست لاثرات محيطى الآلودهازي؛ كاهش استفاده ازز منابع طبيعى؛ بهبود اكوسيستم؛ كاهش & حفاظت و احياء هنابعطبيعى & ? \\
\hline 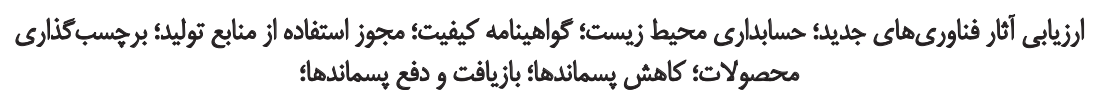 & | مليريت، نظارت و & 3 \\
\hline
\end{tabular}

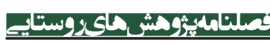

و واحدهاى ثبت معتبر و پاياست. واحد ثبت، واحدى معنى داري

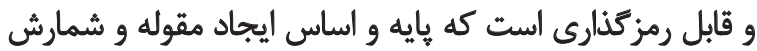
بسامدى واحدهاست (Holsti, 1969).

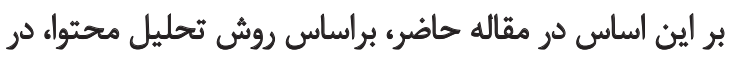

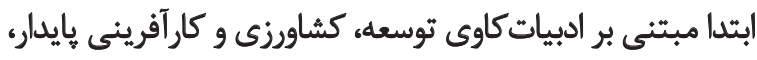

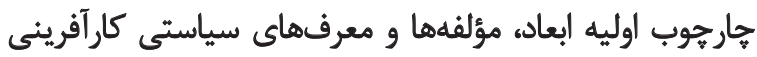

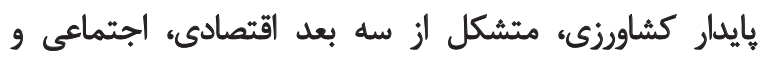

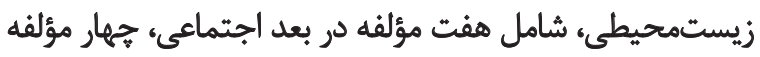

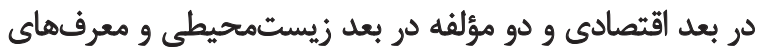

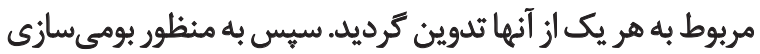

اصطلاح، معرف اهميت آن است. در رونديثوهى، يافتههاى

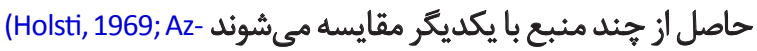
إن \&ia \&arban Astaneh; 2003)

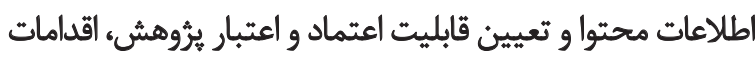

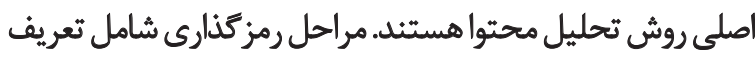

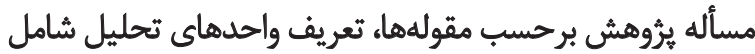

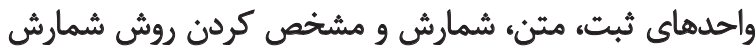

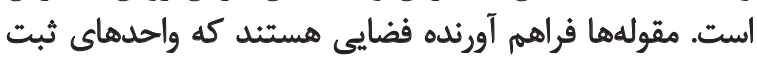

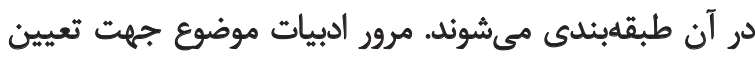

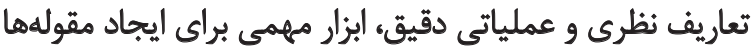




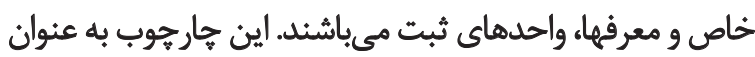

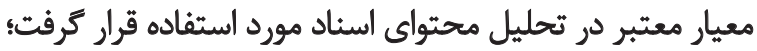

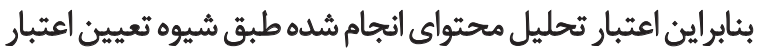

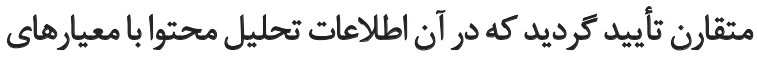

متعدد موجود در منابع معتبر مقايسه ميى شود (Holsti, 1969).

در اين مقاله، اسناد سياستى بالادستى اثر كذار بر سياستخذارى

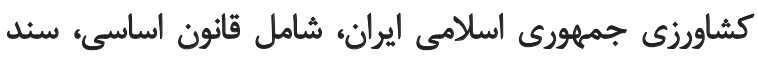

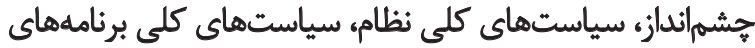

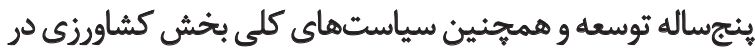

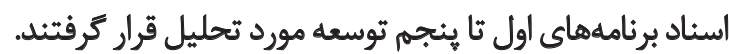

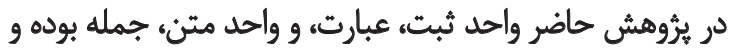

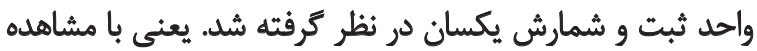

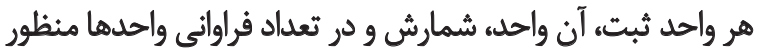

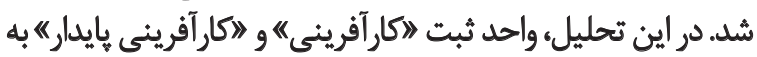

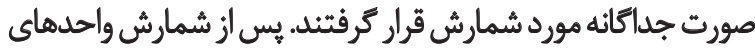

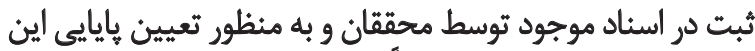

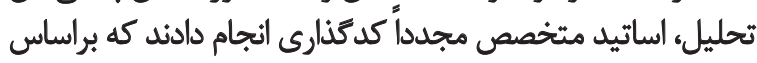

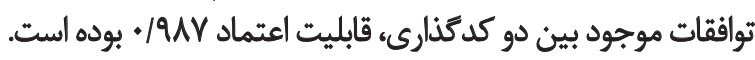

به منظور افزايش توان يردازش دادهها در تحليل محتوا و و

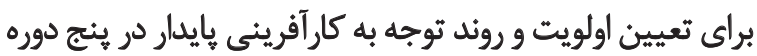

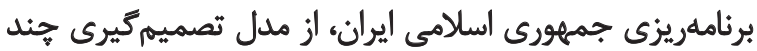

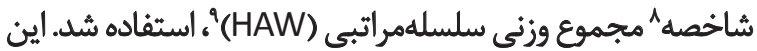

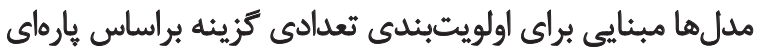

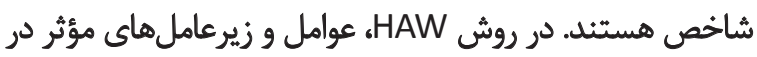

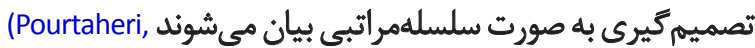

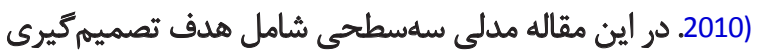

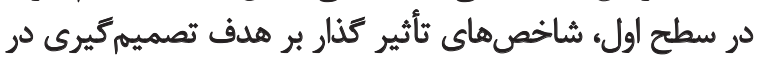

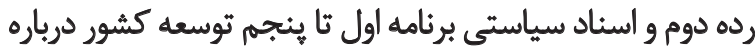

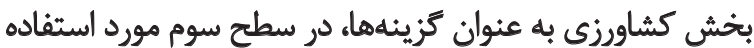

قرار كرفت (تصوير شماره أ)

8. Multiple Attribute Decision Making (MADM)

9. Hierarchical Additive Weighting Method (HAW)
و تعيين اعتبار آنه اين جارجوب براى نظرسنجى در خصوص

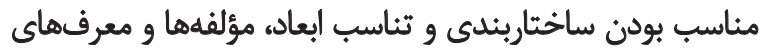

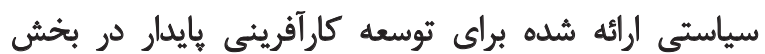

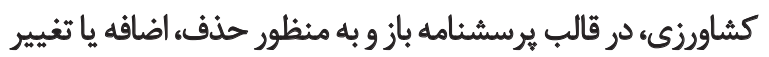

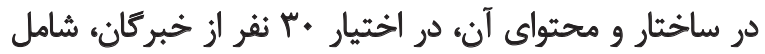

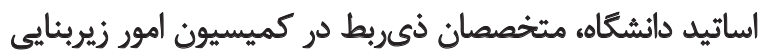

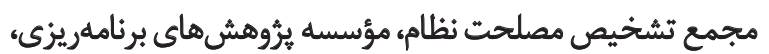

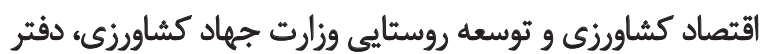

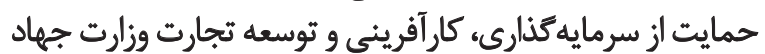

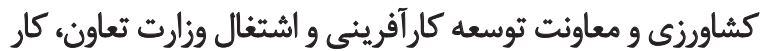
و رفاه اجتماعى قرار داده شد (شايان ذكر است

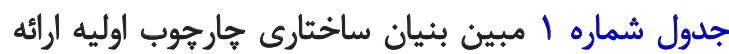

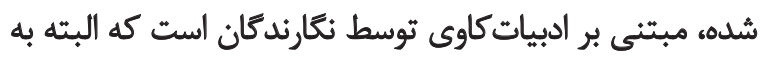

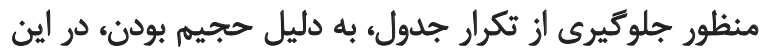

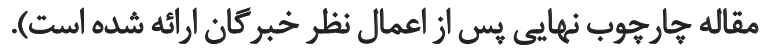

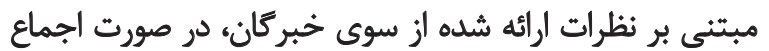

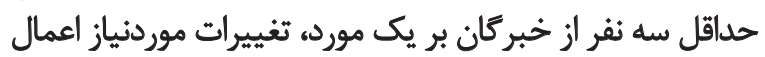

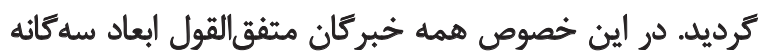

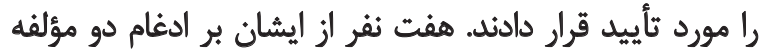

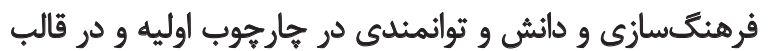

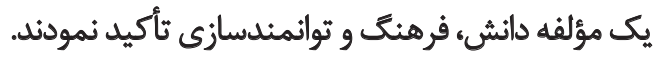

سه نقر حذف شاخص توزيع عادلانه قدرت سياسى در قالب

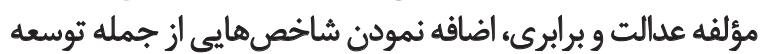

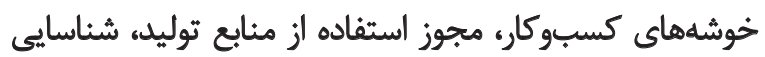

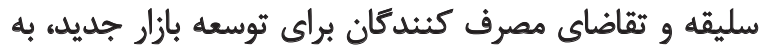

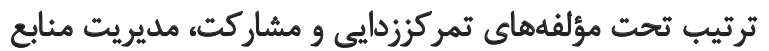

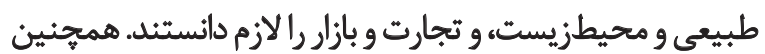

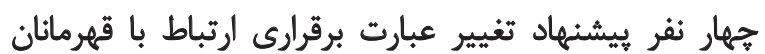

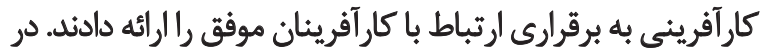

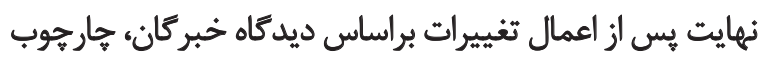

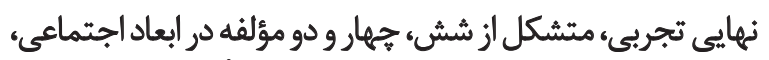

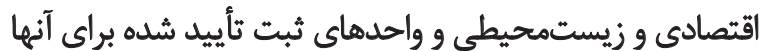

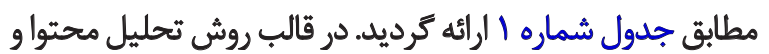

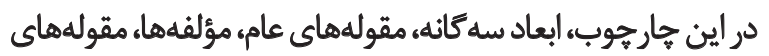

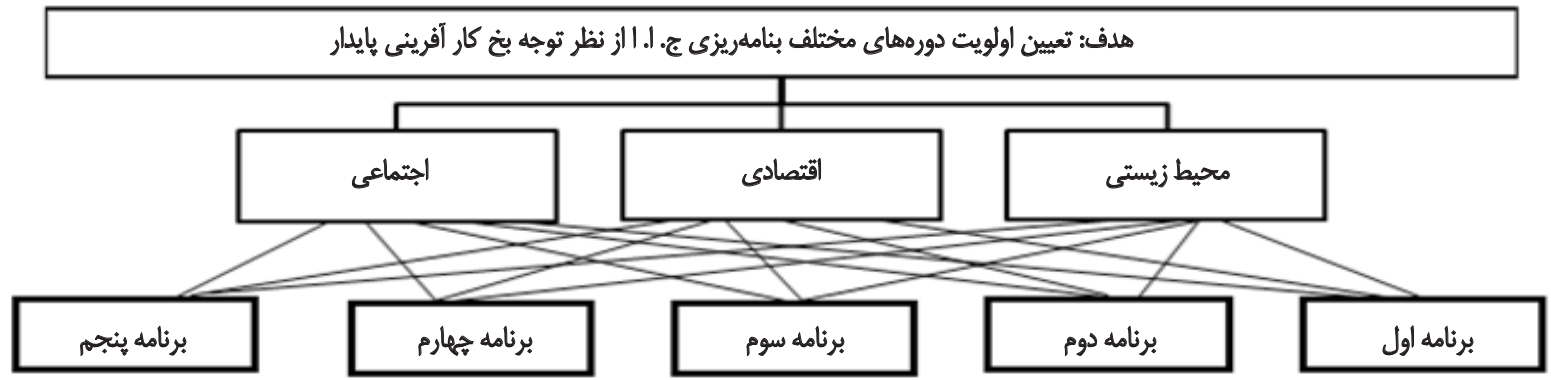




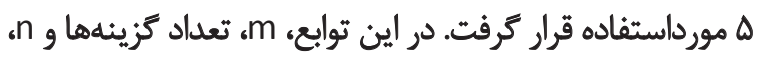
تعداد شاخص:هاست (Pourtaheri, 2010; Azar 2001).

$P_{i j}=\frac{a_{i j}}{\sum_{i=1}^{5} a_{i j}}$

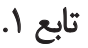

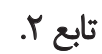

$E_{j}=-K \sum_{i=1}^{m}\left[P_{i j} \ln P_{i j}\right] ; \forall_{j} \quad K=\frac{1}{\ln (m)}$

$d_{j}=1-E_{j} ; \forall_{j}$

$W_{j}=\frac{d_{j}}{\sum_{j=1}^{n} d_{j}}$

$W=W 3 . W 2.1$

در اين هروهش يك هارجوب تجربى كلئكر، بومى و معتبر،

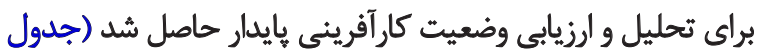

در اين مدلهاء تعيين وزن شاخصهاء براي ارزيابى اهميت

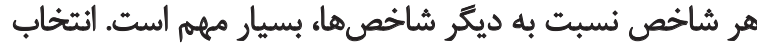

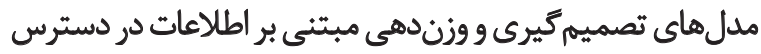

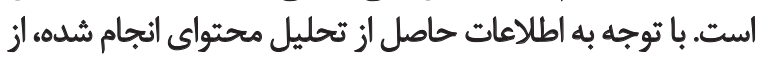

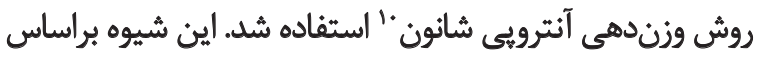

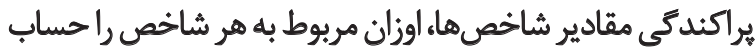

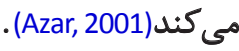

در اين مقاله، براى اولويتبندى برنامهها براساس كامهاى مدائل مدال

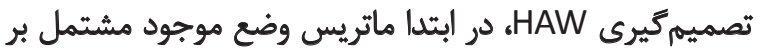

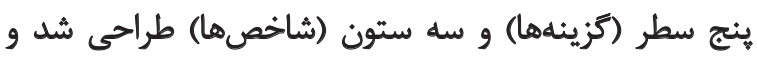

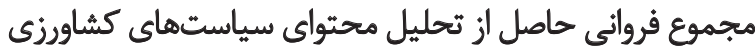

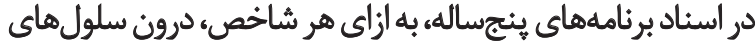

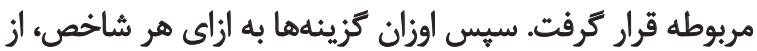

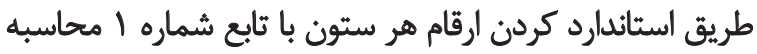

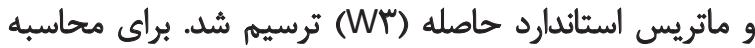

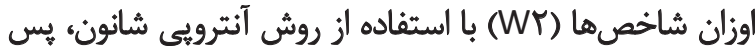

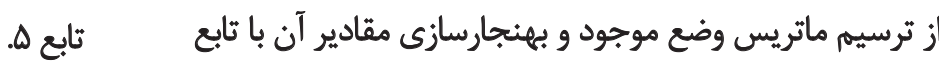

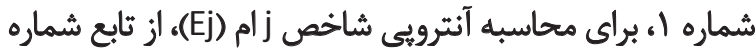

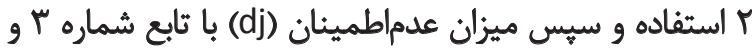

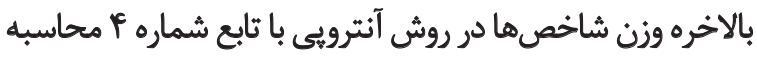

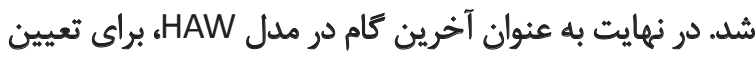

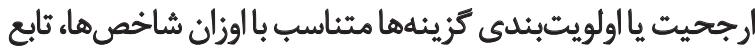

10. Shannon Entropy

جدول r. فراوانى مولفههاو درصد ابعاد كارآفرينى يايدار كشاورزى در اسناد كلان سياستى

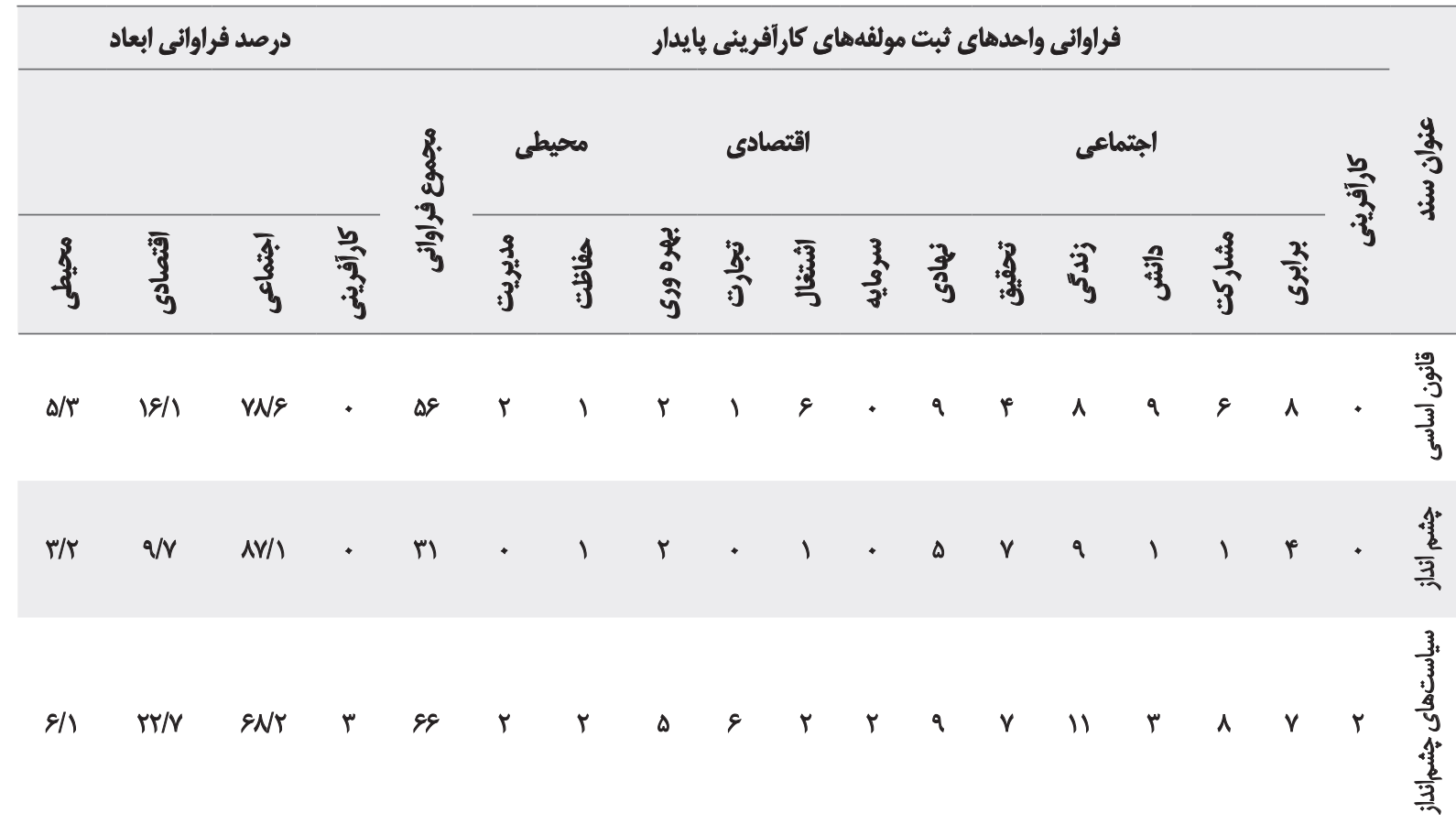


جدول r. فراوانى مولفهها و درصد ابعاد كارآفرينى بايدار كشاورزى در سياستهاى كلى نظام

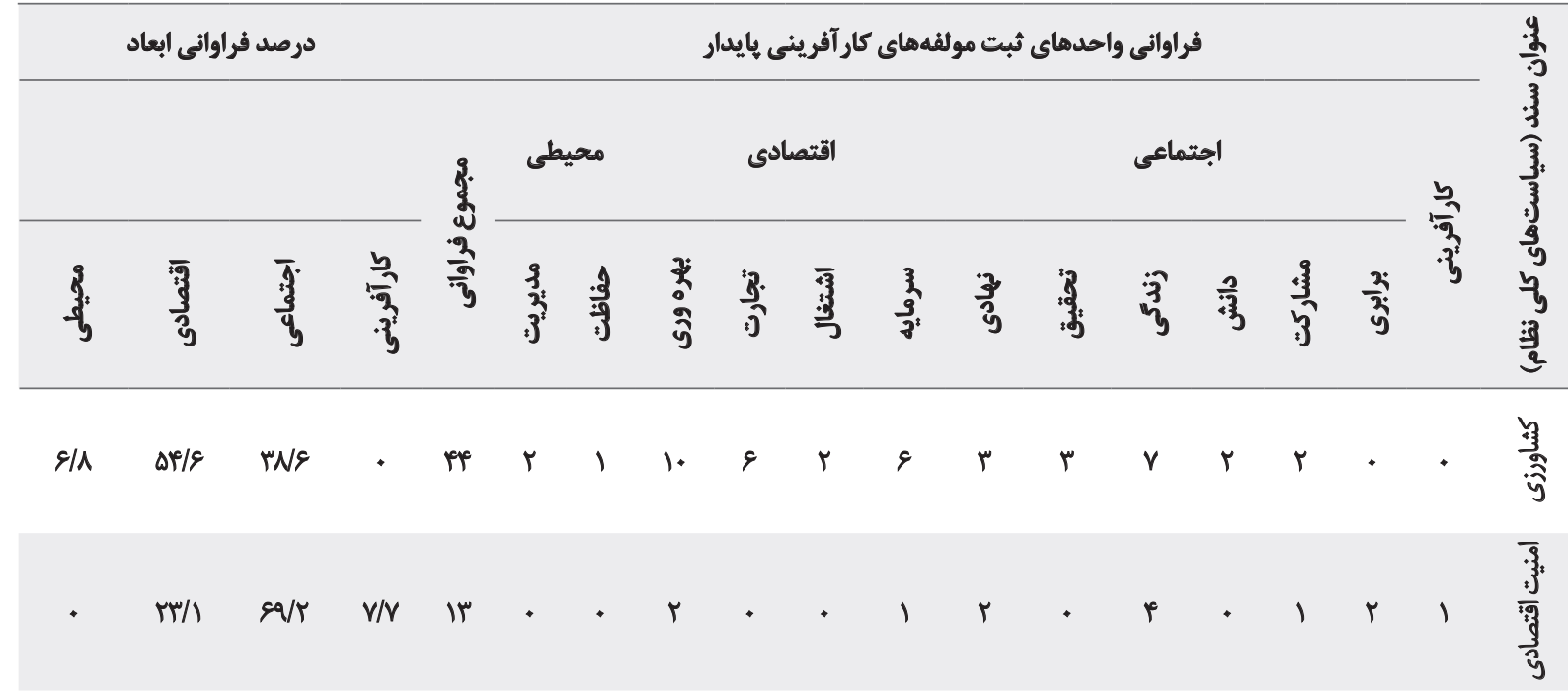

E\&/8 IE/N IE/N $\quad \& \quad \& \quad \cdot 1$

$\frac{3}{3}$

TT/NO IT/O RT/NA

18

$$
\text { - } \quad 1
$$

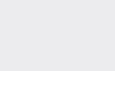

- ria ra $r / 1$ rr

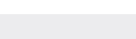

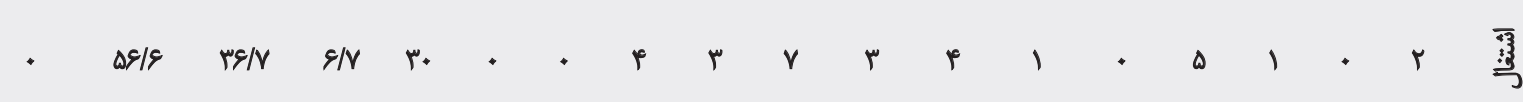

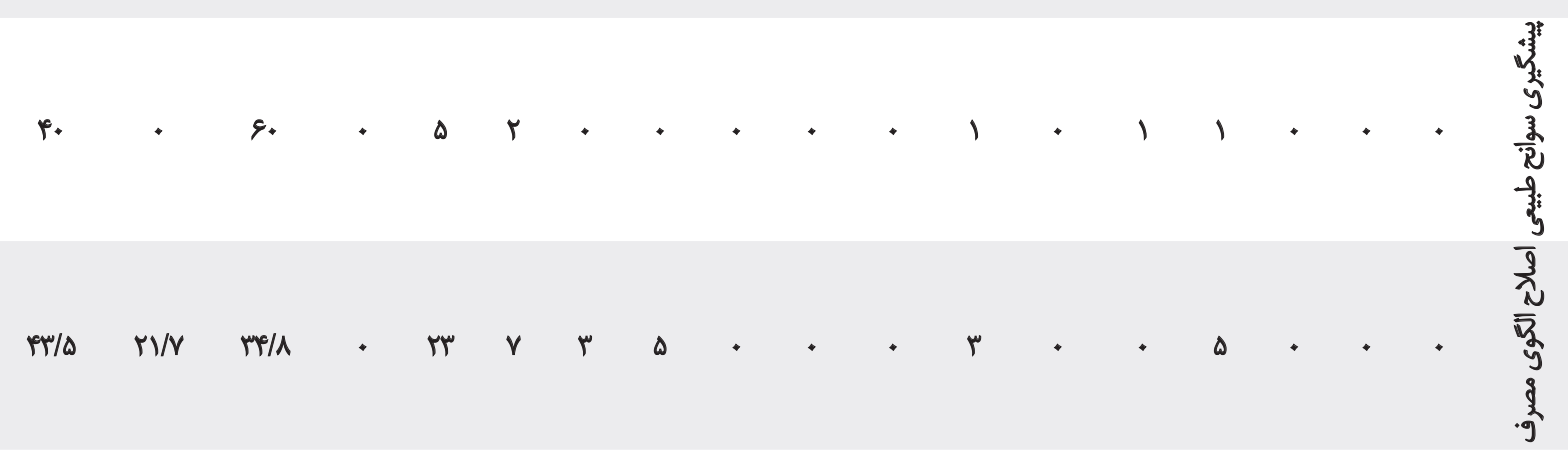

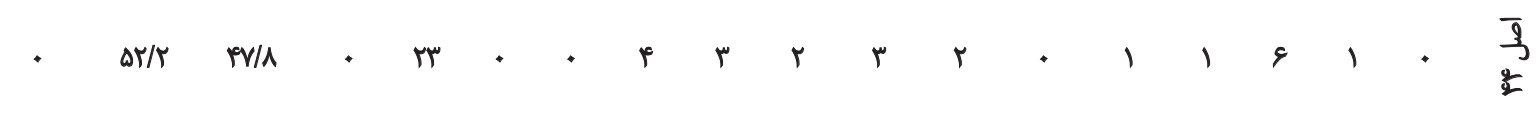

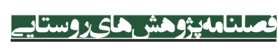

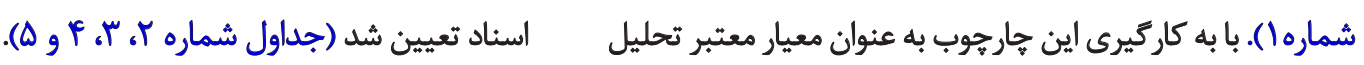

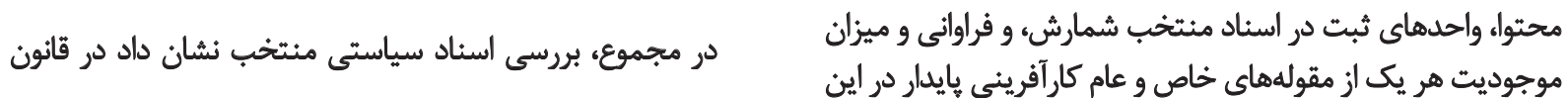


جدول F. فراوانى مولفهها و درصد ابعاد كارآفرينى بايدار كشاورزى در سياستهاى كلى برنامهها

\begin{tabular}{|c|c|c|c|c|c|c|c|c|c|c|c|c|c|c|c|c|c|c|}
\hline \multicolumn{4}{|c|}{ درصد فراوانى ابعاد } & \multicolumn{14}{|c|}{ فراوانى واحدهاى ثبت مولفههاى كار أقرينى يايدار } & \\
\hline & & & & 8. & & & & & اقتم & & & & & & & & \multirow{2}{*}{ 占 } & \\
\hline$\frac{3}{3}$ & 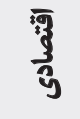 & $\frac{\overline{4}}{4}$ & $\begin{array}{l}\frac{b}{2} \\
\text { ?3 } \\
\text { ?3 }\end{array}$ & $=\frac{2}{3}$ & $\begin{array}{l}\frac{9}{1} \\
3^{3} \\
3^{3}\end{array}$ & $\frac{3}{3}$ & $\begin{array}{l}\dot{3} \\
5 \\
\hat{\sigma} \\
\hat{y}\end{array}$ & $\frac{3}{3}$ & $\begin{array}{l}\overline{4} \\
3 \\
3 \\
3 \\
3\end{array}$ & $\frac{3}{3}$ & के & 8 & भै & 高 & $\frac{4}{3}$ & $\frac{x}{3}$ & & है \\
\hline$\Delta$ & Fa & ه. & - & r. & • & 1 & r & r & r & r & - & 1 & r & r & 1 & $r$ & * & $\begin{array}{l}3 \\
3 \\
2 \\
2\end{array}$ \\
\hline $8 / 1$ & rNE & Q. & p/s & pq & 1 & r & r & r & $\wedge$ & r & $r$ & r & $\Delta$ & r & r & $\Delta$ & r & \\
\hline$P / A$ & ra & $\Delta f$ & $r / r$ & gr & 1 & r & 9 & 9 & $p$ & f & $\Delta$ & $\Delta$ & 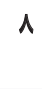 & $\Delta$ & 8 & a & $r$ & $\frac{3}{2}$ \\
\hline $1 / 0$ & 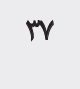 & S1/D & • & $9 \Delta$ & 1 & • & 8 & $\Delta$ & $r$ & 11 & $v$ & $v$ & 11 & 8 & f & $\Delta$ & • & $3^{*}$ \\
\hline
\end{tabular}

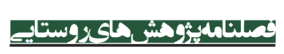

جدول ه. فراوانى موالفها و درصد ابعاد كارآفرينى هايدار كشاورزى در سياستهاي كثاورزى برنامهها.

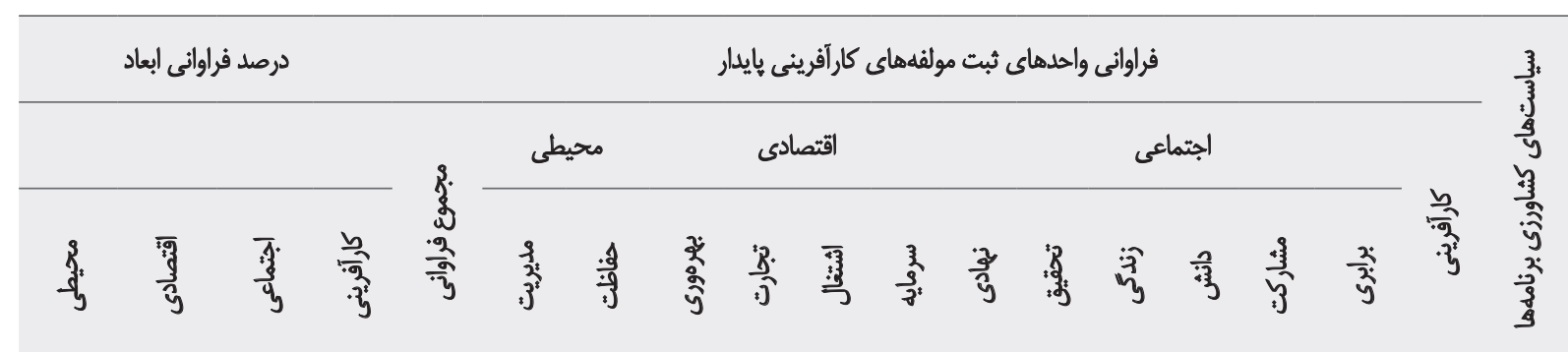

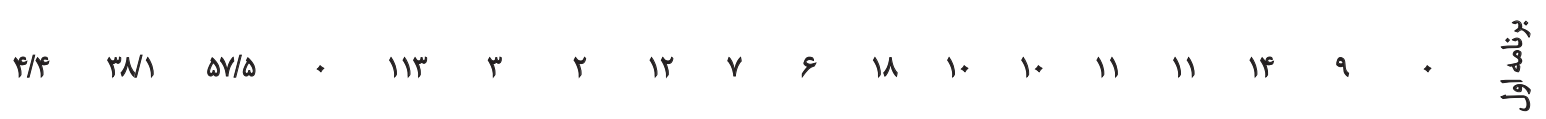

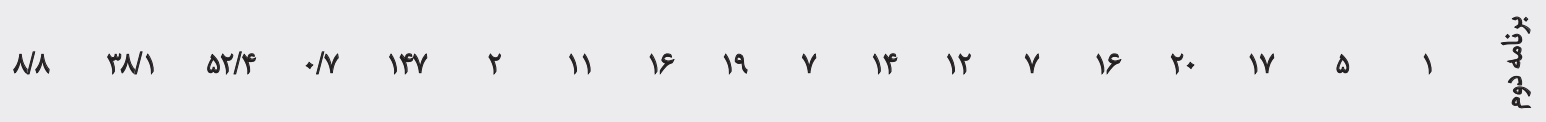

ir r. ra $\quad$ r

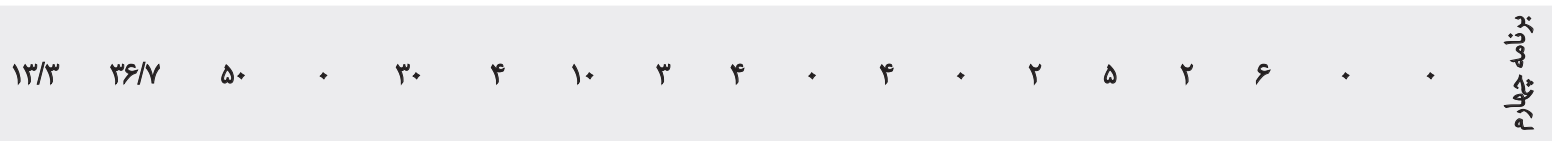

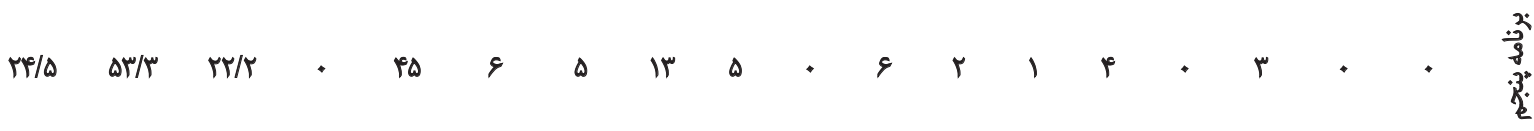




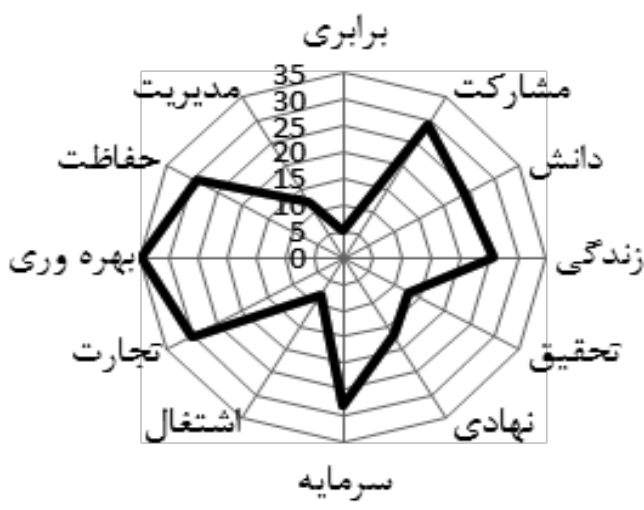

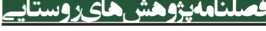

تصوير با. وضعيث توجه به مولفههاي كارآفريني هايدار در سياستهاى براي

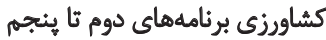

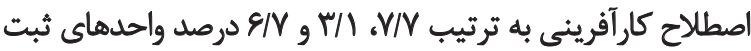

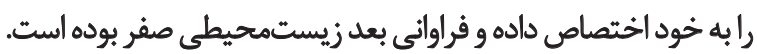

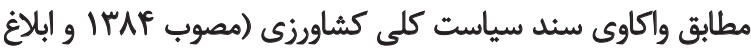

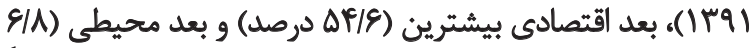

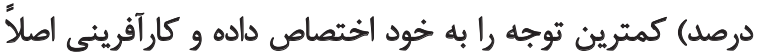
مورد توجه قرار نتُرفته است توريه

مطابق جدول شماره fا، در همه اسناد سياستهاى كلى برنامهها،

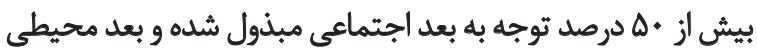

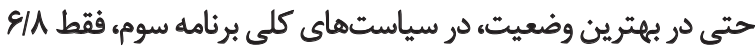

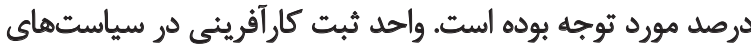

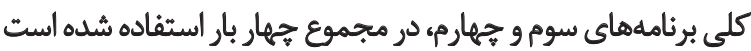
كه باوجود اين، در برنامه ينجمم مغفول مانده است.

براساس يافتههاى درج شده در جدول شماره ها، واكاوى

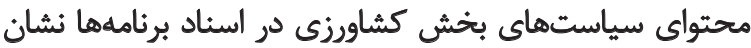

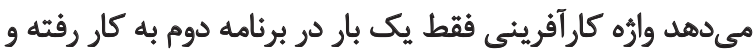

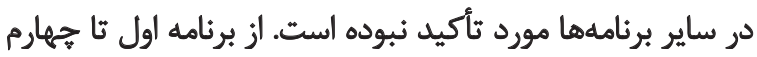

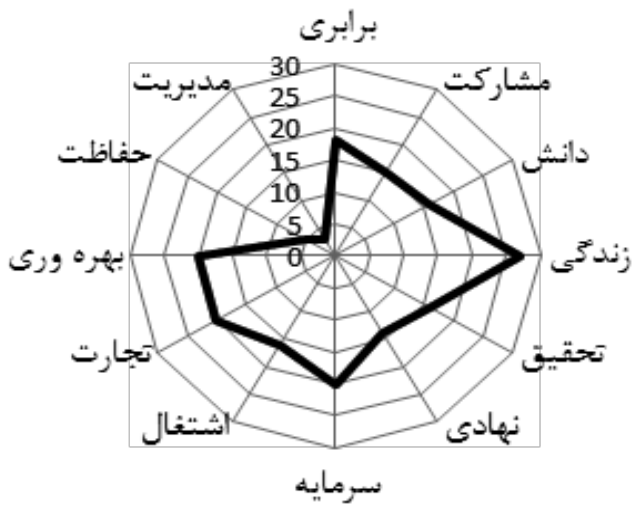

\section{كملفامس}

تصوير r. وضعيث توجه به مولفهام كارآفريثى بايدار در سياستهاي كلى

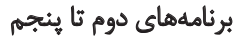

اساسى و سند جشمانداز بيستساله كشور، به عبارت توسعه هايدار

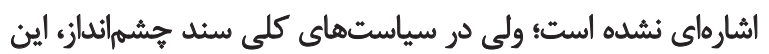

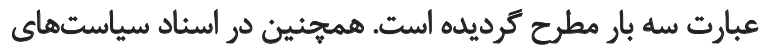

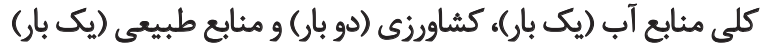

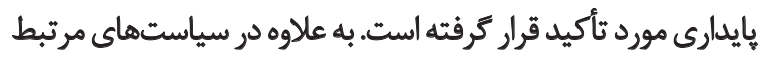

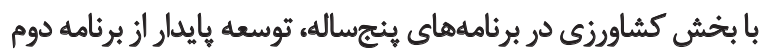

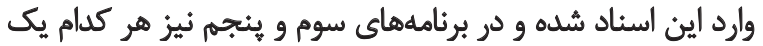

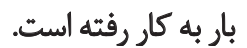

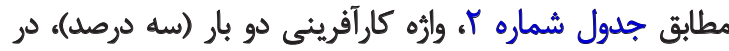

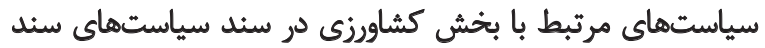

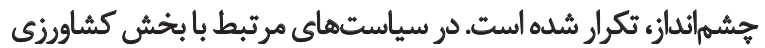

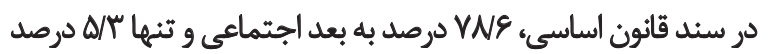

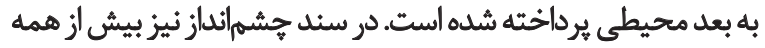
بعد اجتماعى (AV/I درصد) مورد توجه قرار كرفته است. مطابق يافتههاى درج شده در جدول شماره با، در در اسناد سياستهاى كلى امنيت اقتصادى، تشويق سرمايهذارى و اشتغال،

جدول \& ماتريس تصميمكيرى وضع موجود

\begin{tabular}{|c|c|c|c|}
\hline محيطى & اقتصادى & اجتماعى & \\
\hline$\Delta$ & $r r$ & EQ & برنامه 1 \\
\hline ir & $\Delta$ & $w$ & برنامه r \\
\hline$r$ & 1. & ir & برنامه r \\
\hline 10 & 11 & 10 & برنامه P \\
\hline 11 & Mp & 1. & برنامه ه \\
\hline re & IrF & ivq & جمع \\
\hline
\end{tabular}


جدول V. ماتريس مقادير استاندارد شده

\begin{tabular}{|c|c|c|c|}
\hline هحيطى & اقتصادى & اجتماعى & \\
\hline.$/ 11$ & $\cdot / \pi$ & . /re & برنامه اول \\
\hline.$/ M A$ &.$/ 49$ &.$/ R T$ & برئامه دوم \\
\hline $.1 \cdot v$ &.$/ \cdot V$ &.$/ \cdot V$ & برنامه سووم \\
\hline.$/ r$. & $.1 \cdot 1$ & $.1 \cdot 1$ & برئامه جهارم \\
\hline.$/ M F$ & $+/ \mathrm{V}$ & .1 .8 & يرثامه يَتجمم \\
\hline
\end{tabular}

政

جدول A. آنترويى، مقادير عدم اطمينان و وزن شاخصهاى كار آفرينى هايدار

\begin{tabular}{|c|c|c|c|}
\hline هحيطى & اقتصادى & اجتماعى & \\
\hline - /9r & $\cdot M A$ & $\cdot / \Lambda$ & أتنتوويى شاخصها (Ej) \\
\hline$+1+1$ &.$/ 1 T$ & $\cdot \pi$ & مقادير عدم اطمينان (dj) \\
\hline.$/ \pi$ &.$/ \mu$ &.$/ \Delta$ & وزن شاخصها (Wj) \\
\hline
\end{tabular}

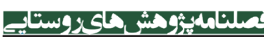

و همجنين برابرى و اشتغال در سياستهاي بخش كشاوري توجه اندكي مبذول شده است.

به منظور تعيين اولويت و روند توجه به ابعاد مختلف كارآئرينى دئي

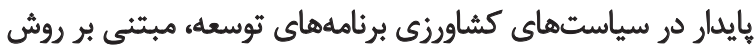

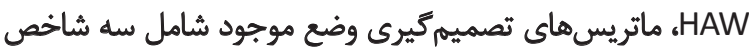

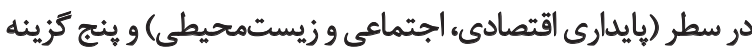

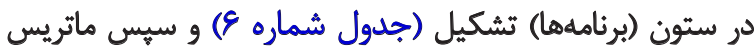

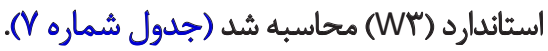
اوزان محاسبه شده هر شاخص با روش آنترويى، در جدول شماره

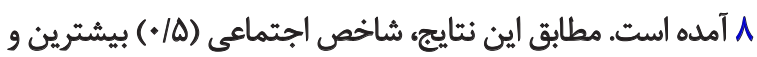

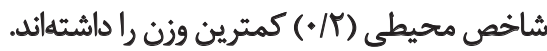

براساس اوزان حاصله، اولويت برنامههاي ينجساله توسعه كشور به

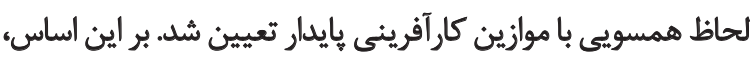

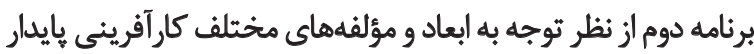

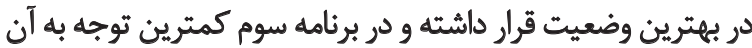
مبذول شده است (جدول شماره 9 9)
حدود • ه درصد واحدهاي ثبت مثعلق به بعد اجتماعى بوده و

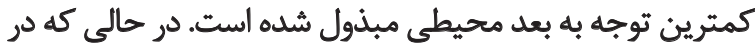

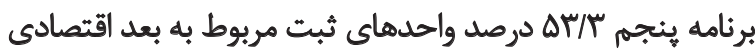

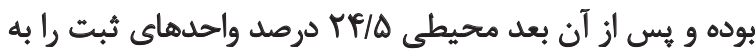

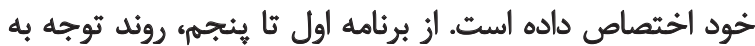

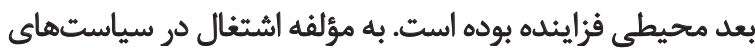

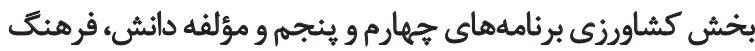

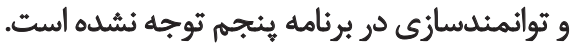

مطابق يافتههاى جداول r تا ها در هيج يك از اسناد سياستي عبارت "كار آفرينى هايدارئه وجود نداشته است

وضعيث توجه به مقولههاي خاص معرف كارآفرينى يايدار

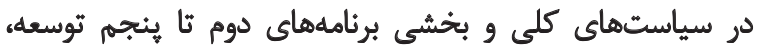

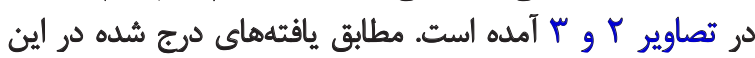

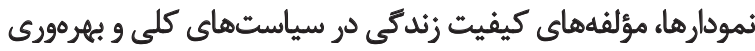

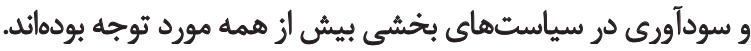

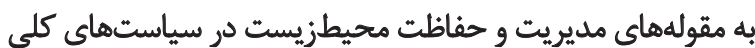

جدول ج. درجه ارجحيت برئامهها و وضعيت اولويت آنها

\begin{tabular}{|c|c|c|c|c|c|}
\hline برئامه ه & برنامه P & برنامه" & برثامه Y & برثامها & درجه الرجحيت \\
\hline .1179 &.$/ 1 T F$ & $\% \gamma$ & $\cdot / \mathrm{HM}$ & ארa & \\
\hline
\end{tabular}

بونامه سوم>برنامه جيمارم>برنامه يُنجم>برنامه اول>برنامه دوم

وضعيت اولويت 
مورد توجه قرار نكرفتيه است.

ז. ورود انديشههاي بايدارى و كار آفرينى در اسناد سياستى كشور

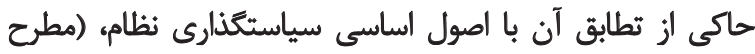

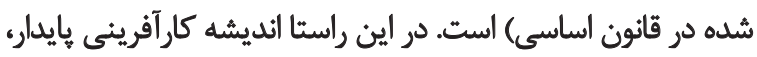

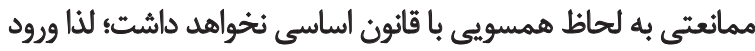

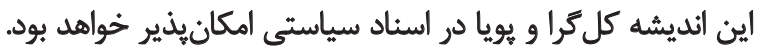

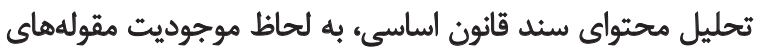
معرف كارآفرينى بايدار، يشتيبان بودن اين سند را تأييد ميثمايد. لمايد. r. براساس واكاوى سند جشمانداز بيستساله و همجينين

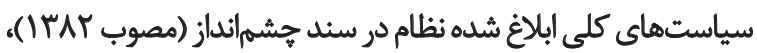

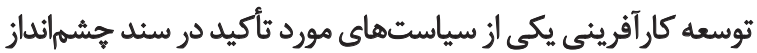

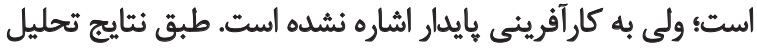

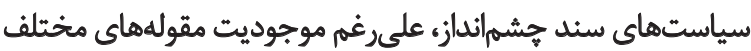

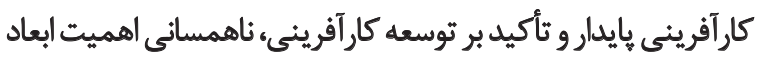

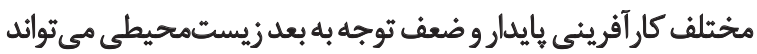

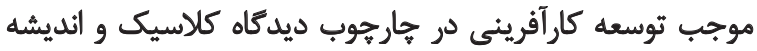

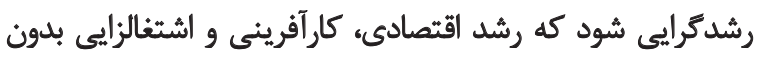

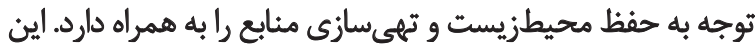

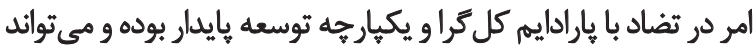

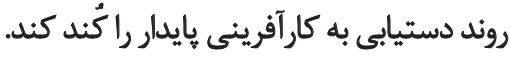

f. سياستهاى بخشى، ابلاغ شده است. در اين سياستها، براس براساس

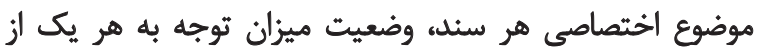

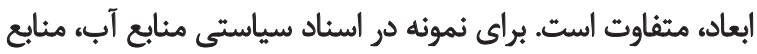

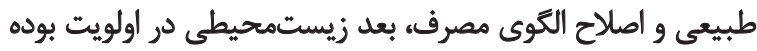

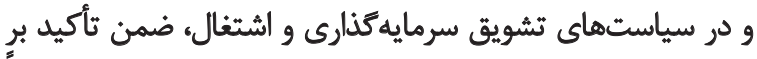

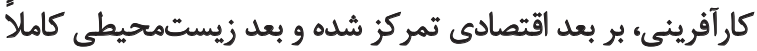

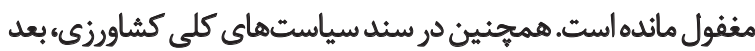

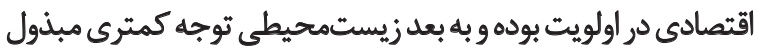

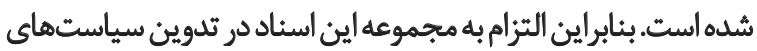

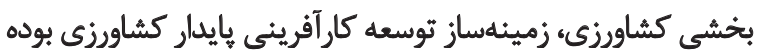

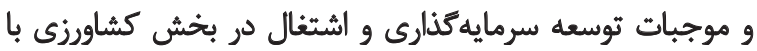

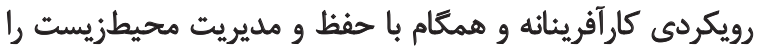

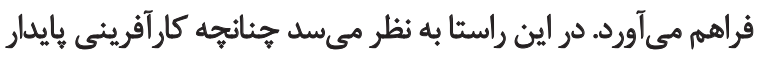

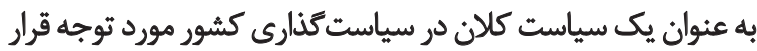

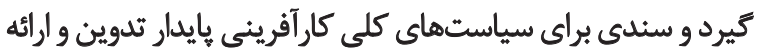

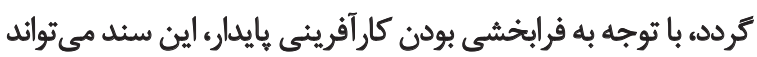

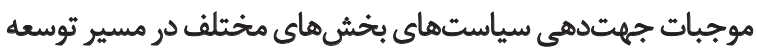
بايدار مبتنى بر كار آفرينى رافراهم آوردي

ه. سياستهاى كلى برنامهائ بينجساله توسعه كشور، از ديكر

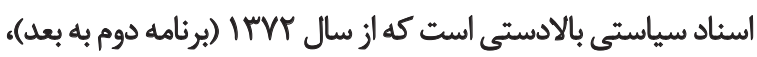

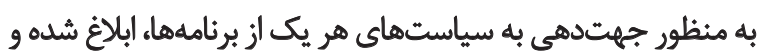

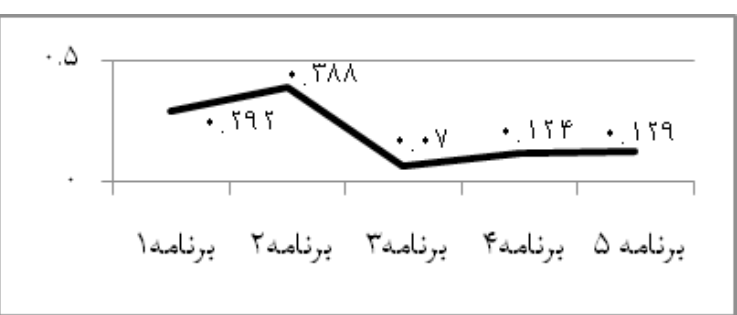

\section{Ex}

تصوير ". روند ميزان توجه به ابعادكار آفرينى بايدار در برنامهاى بنتجاله توسعه

مطابق يافتهاى فوق، وضعيت توجه به ابعاد مختلف كارآ آفرينى

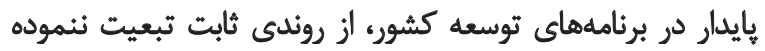

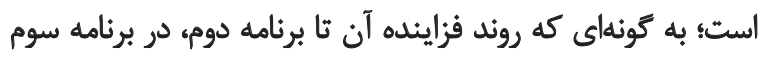

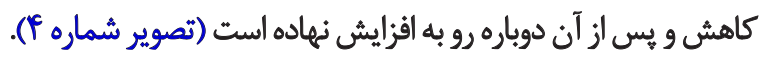

\section{بحث و نتيجهيَيرى}

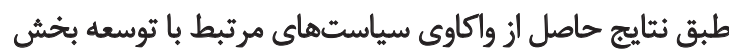

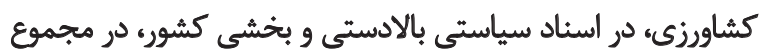

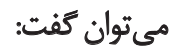

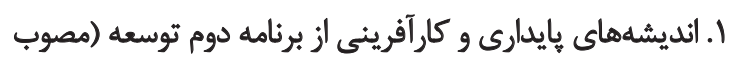

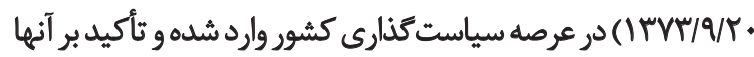

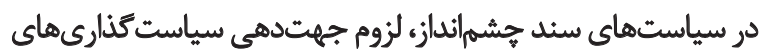

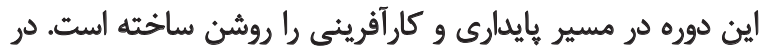

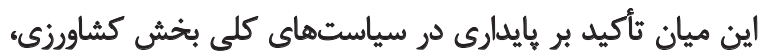

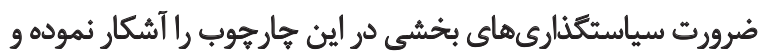

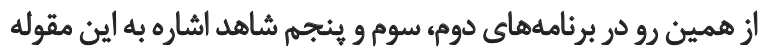

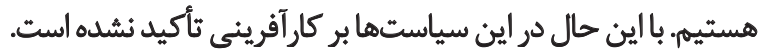

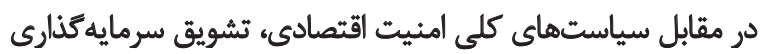

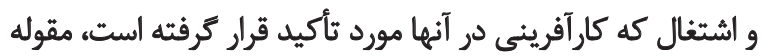

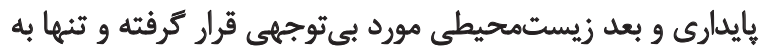
ابعاد اقتصادى و اجتماعى يرداخته شده است.

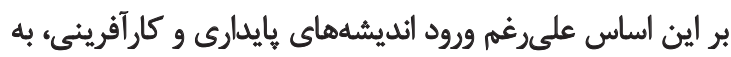

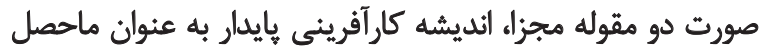

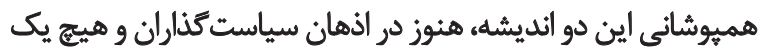

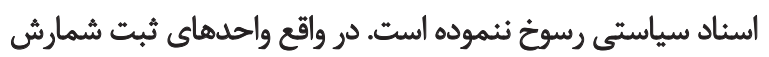

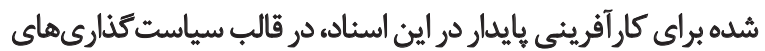

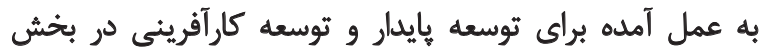

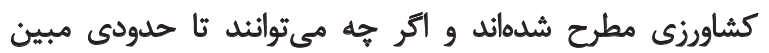

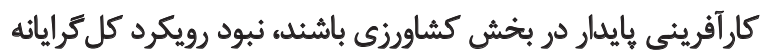

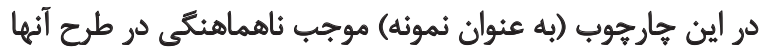

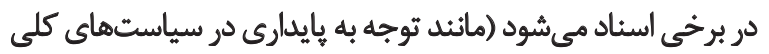

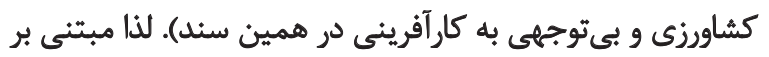

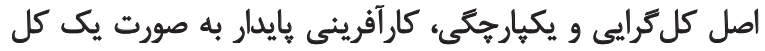


در سياستهاي كلى و بخش كشاورزى برثامههاي توسعاه، نمى توان

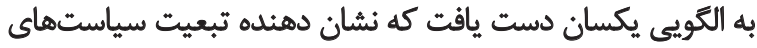

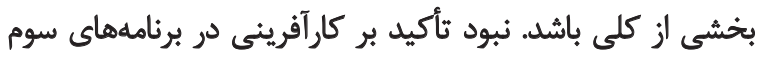

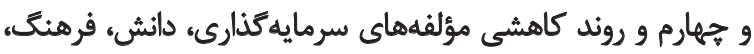
توانمندسازى و تحقيق و توسعه از مصاديق اين امر است.

هـ در مجموع، نثايج حاصل از واكاوى كليه اسناد سياستى فوق

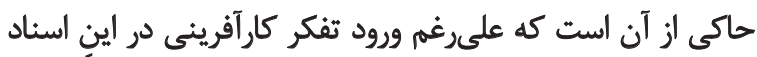

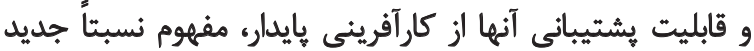

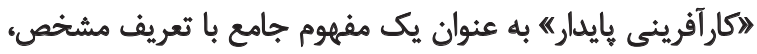

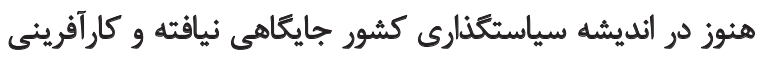

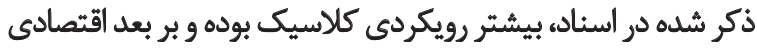

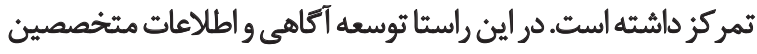

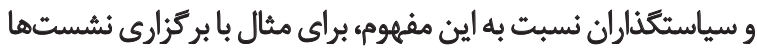

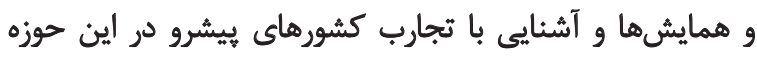

$$
\text { بيشنهاد هي وشود. }
$$

9. علاوه بر موارد فوق طى فرايند واكاوى اسناد برنامههاى

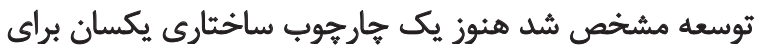

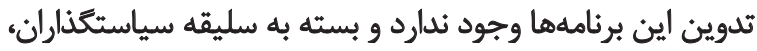

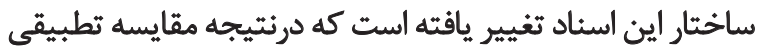

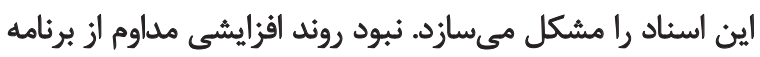

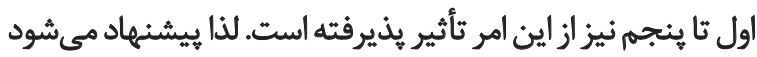

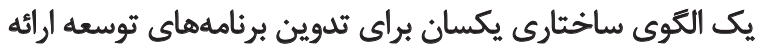

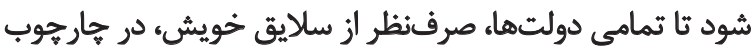

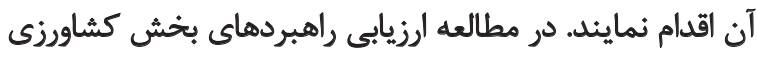

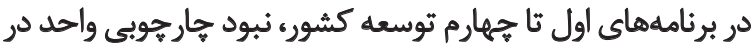

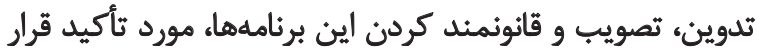

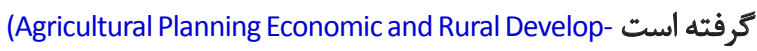
.ment Research Institute, 2010)

$$
\text { تشكر وقدردانى }
$$

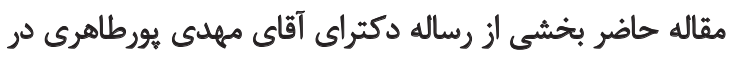

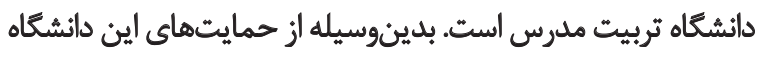

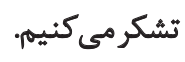

اتتظار بر آن بوده برئامههاي توسعه و سياستهاى بخشى در جهاي

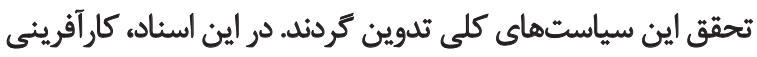

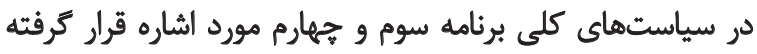

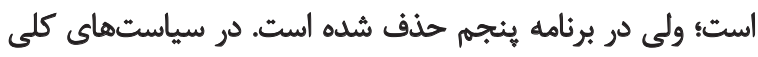

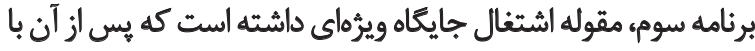

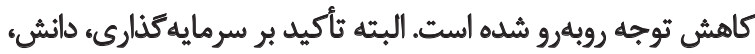

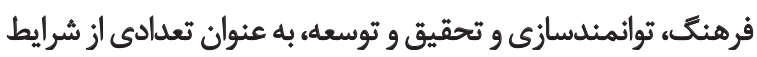

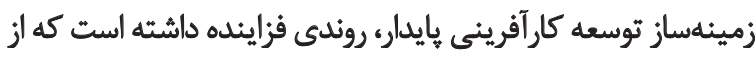

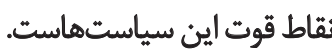

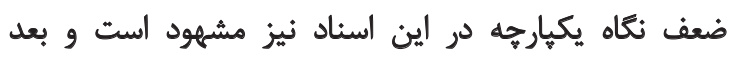

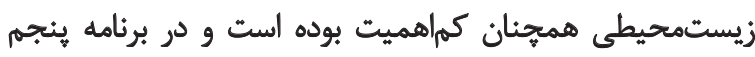

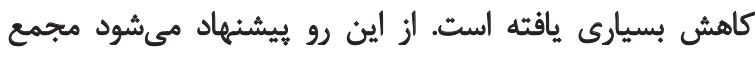

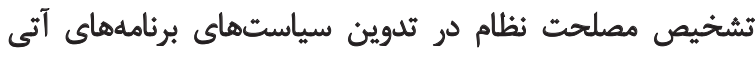

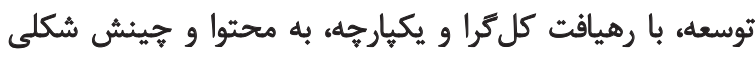

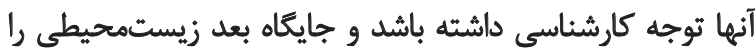

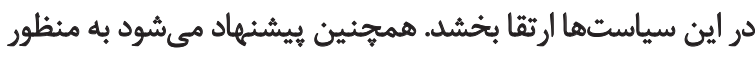

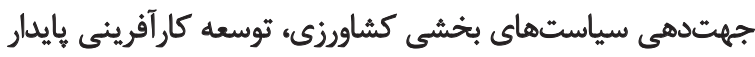

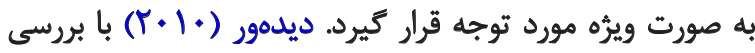

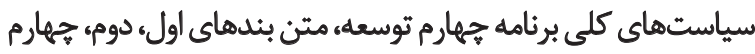

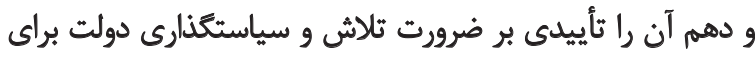

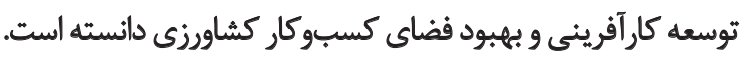
و. در اسناد سياستهاى بخش كشاورزى برنامههاي توسعه،

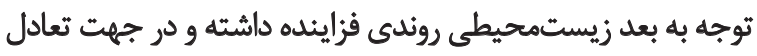

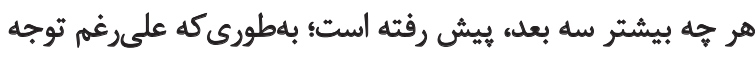

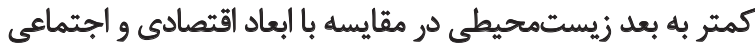

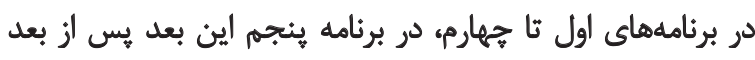

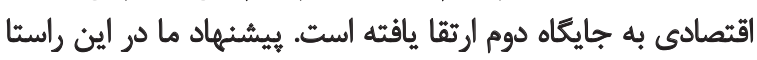

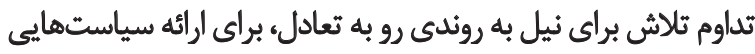

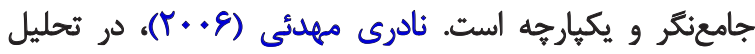

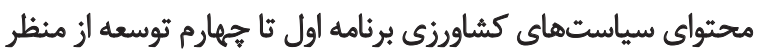

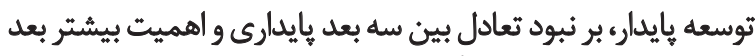
اجتماعى در اين برنامهها تأكيد نمود.

واحد ثبت كارآفرينى فقط در سياستهاي برنامه دوم مطرح بوده

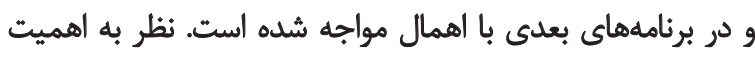

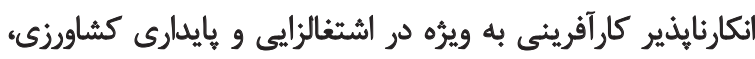

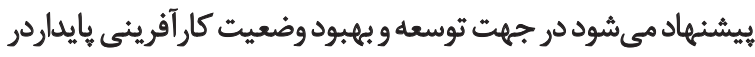

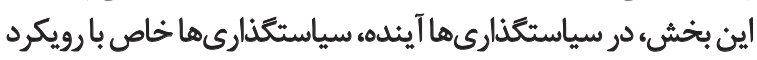

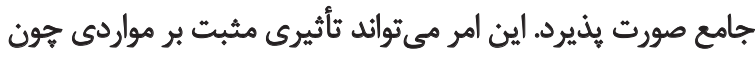

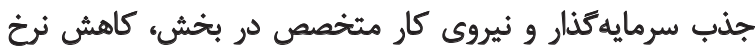

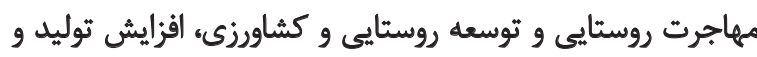

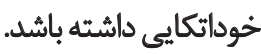

V. در مطالعه تطبيقى روند توجه به مؤلفههاى كارآفرينى هايدار، 


\section{References}

Agricultural planning economic and rural development research institute. (2010). [Assessing the strategies of agriculture sector in fiveyear development plans from first to fifth plan (1989-2009), Unpublished research project (Persian)]. Tehran: Agricultural Planning Economic and Rural Development Research Institute.

Ahmadpour Dariani, M. (2004). [Entrepreneurship: Definitions, theories and models (Persian)]. Tehran: Pardis

Azar, A. (2001). [Extending and developing the Shannon entropy for data process in content analysis (Persian)]. Journal of Humanities, 11(37-38), 1-18.

Azkia, M., \& Darban Astaneh, A. (2003). [Applied research methods (Persian)] (Vol. 1). Tehran: Keyhan Publication.

Birner, R. \& Resnick, D. (2005). Policy and politics for smallholder agriculture. In IFPRI, ODI, Imperial College of London (Ed.), The Future of Small Farms: Proceedings of a Research Workshop, 2005, (pp. 283-311). London: WYE.

Bygrave, W. D. \& Zacharakis, A. (2011). Entrepreneurship (2 ${ }^{\text {nd }}$ Ed.). Hoboken: John Wiley \& Sons.

Carreón J. R., Faber N. R., Jorna, R. J., \& Haren, R. V (2010). A knowledge approach to sustainable agriculture. In M. Behnassi, S. Draggan, S. Yaya (Eds.), Global Food Insecurity, Rethinking Agricultural and Rural Development Paradigm and Policy. (pp. 11-20). Berlin: Springer.

Campbell, T. \& Barrett, H. (2008). Increasing entrepreneurship in agriculture in an economically depressed region. Journal of Extension, 46(5), Research in Brief, 5RIB2.

Cohen, B., \& Winn, M. I. (2007). Market imperfections, opportunity and sustainable entrepreneurship. Journal of Business Venturing, 22(1), 29-49. doi: 10.1016/j.jbusvent.2004.12.001.

Central bank of the Islamic Republic of Iran.(2012). [Economic report and balance sheet of central bank of the I.R.I year 2009 (Persian)]. Tehran: Central Bank of the Islamic Republic of Iran.

Danaie Far, H., Forouhi, M., \& Salehi, A. (2007). [Improving Entrepreneourship in Iran: An analysis on the role of the government (Persian)]. Iranian Journal of Trade Studies, 11(42), 221-262.

Davari, A. (2011). [Appropriate model for entrepreneurship development by Iran government (Persian)] [PhD. thesis]. Tehran: Allameh Tabataba'i University.

Didehvar, F. (2010). [Designing the model of institutionalizing agricultural entrepreneurship subsector of greenhouses (Persian)] [PhD. thesis]. Tehran: Tarbiat Modares University.

Eskandari, F. (2006). [Strategies to develop entrepreneurship into the Iranian higher agricultural education system (Persian)] [PhD. thesis]. Tehran: University of Tehran.

Fischer Boel, M. (2006). The European model of agriculture: Challenges ahead. Paper presented at The Meeting of Ministers of Agriculture, Oulu, Finland, 26 September 2006.

Food and Agriculture Organization. (2012). Towards the future we want: End hunger and make the transition to sustainable agricultural and food systems. Rome: Food and Agriculture Organization.

Hertin, J., Berkhout, F., Moll, S., \& Schepelmann, P. (2001.) Indicators for monitoring integration of environment and sustainable development in enterprise policy. SPRU - Science and Technology Policy Research. Brighton: University of Sussex.

Hoffman, A. N. (2007). A rough guide to entrepreneurship policy. In D. B. Audretsch, I. Grilo, \& R. Thurik, (Eds.), Handbook of Research on Entrepreneurship Policy (pp. 140-171). London: Edward Elgar.

Holsti, O. R. (1969). Content analysis for the social sciences and humanities [N. Salarzadeh Amiri Persian trans]. Tehran: Allameh Tabatabaii University.

Isenberg, D. (2011). The entrepreneurship ecosystem strategy as a new paradigm for economic policy: Principal for cultivating entrepreneurship. Massachusetts: Babson Entrepreneurship Ecosystem Project.

Katsarova, I. (2013). The common agricultural policy after 2013. Brussels: European Commission of Agriculture and Rural Development.

Kelley, D., Bosma, N., \& Amorós, J. E. (2010). Global Entrepreneurship Monitor, 2010 Global Report. Massachusetts: Babson College, Santiago: Chile Universidad del Desarrollo.

McElwee, G. (2006). The enterprising farmer: A review of entrepreneurship in agriculture. Royal Agricultural Society of England Journal, 167, 66-75.

Management and Planning Organization. (2006.) [The collection of national development documents in fourth economic, social and cultural development plan of I.R.I. Sectorial development documents, production affairs (Persian)] (Vol. 4). Tehran: Management and Planning Organization

Ministry of Agriculture-Jahad. (2008). [National document of developing agriculture and natural resource sector in $4^{\text {th }}$ development Plan (Persian)]. Tehran: Ministry of Agriculture-Jahad.

Motiee L., S. H., Rezvani, M. R., Faraji S., H. \& Khajeh Shahkoohi, A. R. (2010). [Analysis of sustainability of family and rural production cooperative farming systems (Case study: Agh-Ghala township: Golestan Province) (Persian)]. Iranian Journal of Agricultural Economics and Development Research, 41(3), 323-333.

Naderi Mahdei, K. (2006). [Analyzing agricultural development policies for the purpose to formulating appropriate model of agricultural sustainable development policies in Hamadan province (Persian)] [PhD. thesis]. Tehran: University of Tehran.

Pacheco, D. F., Dean, T. J., \& Payne, D. S. (2010). Escaping the green prison: Entrepreneurship and the creation of opportunities for sustainable development. Journal of Business Venturing, 25(5), 464-480. doi: 10.1016/i.jbusvent.2009.07.006

Pourtaheri, M.(2010). Application of multi-attitude decision making methods in geography. Tehran: SAMT Publication.

Pretty, J. N. (1998). Supportive policies and practice for scaling up sustainable agriculture. In N. G. Roling, \& M. A. E. Wagemakers, (Eds.), Facilitating Sustainable Agriculture: Participatory Learning and Adaptive Management in Times of Environmental Uncertainty (pp. 2345). London: Cambridge University Press.

Rogers, P. P., Jalal, K. F. \& Boyd, J. A. (2008). An introduction to sustainable development. London: Earthscan Publishing.

Rokneddin Eftekhari, A. \& Sojasi Qedari, H. (2010). [Rural development with emphasis on the entrepreneurship (definitions, attitudes and experiments) (Persian)]. Tehran: SAMT Publication. 
Schaltegger, S., \& Wagner, M. (2011). Sustainable entrepreneurship and sustainability innovation: categories and interactions. Business Strategy and the Environment, 20(4), 222-237. doi: 10.1002/ bse. 682

Schøtt, T. \& Jensen, K. W. (2008). The coupling between entrepreneurship and public policy: Tight in developed countries but loose in developing countries. Estudios de Economia, 35(2), 195-214. doi: $10.4067 /$ S0718-52862008000200005

Sharifzadeh, A. Arabiuon, A. Yadollahi Farsi, J., \& Razavi, S. M. (2009). The role of entrepreneurship in sustainable agriculture development. In J. Yadollahi F. (Ed), Encyclopedia of Entrepreneurship (2 $2^{\text {ed }}$ Vol.). (pp. 1480-1488,) Tehran: Encyclopedia Foundation of Iran and Labor and Social Security Institute.

Sojasi Qeidari, H. (2008). [Study and analysis the factors affected agricultural entrepreneurship development in rural arae, case study: Khodabande Province (Persian)] [MSc. thesis]. Tehran: Tarbiat Modares University.

Spence, M., Ben Boubaker Gherib, J., \& Ondoua Biwolé, V. (2010). Sustainable entrepreneurship: Is entrepreneurial will enough? A north-south comparison. Journal of Business Ethics, 99(3), 335-367. doi: 10.1007/s10551-010-0656-1

Stevenson, 1. \& lundstrom, A. (2007). Dressing the emperor: The fabric of entrepreneurship policy. In D. B. Audretsch, I. Grilo, \& R Thurik. (Eds.). Handbook of Research on Entrepreneurship Policy. (pp. 94-129). London: Edward Elgar.

Thurik, A. R. (2009). Entreprenomics: Entrepreneurship, economic growth and policy. In Z. Acs, D. B. Audretsch, R. J. Strom (Eds). Entrepreneurship, Growth and Public Policy (pp. 219-249). London: Cambridge University Press.

United nations conference on trade and development. (2012). Entrepreneurship policy framework and implementation guidance. New York: United Nation.

World Bank. (2012). Inclusive green growth: The pathway to sustainable development. Washington, D. C.: World Bank.

York, J. G., \& Venkataraman, S. (2010). The entrepreneur-environment nexus: Uncertainty, innovation, and allocation. Journal of Business Venturing, 25(5), 449-463. doi: 10.1016/j.jbusvent.2009.07.007 